\title{
Photodissociation Pathways of 1,1-Dichloroacetone
}

\author{
Maria J. Krisch, ${ }^{\dagger}$ M. Justine Bell, Benjamin L. FitzPatrick, Laura R. McCunn, \\ Kai-Chung Lau, ${ }^{\perp}$ Yi Liu, ${ }^{\S}$ and Laurie J. Butler*
}

The James Franck Institute and Department of Chemistry, The University of Chicago, Chicago, Illinois 60637

Received: November 30, 2006; In Final Form: April 27, 2007

\begin{abstract}
We present a comprehensive investigation of the dissociation dynamics following photoexcitation of 1,1dichloroacetone $\left(\mathrm{CH}_{3} \mathrm{COCHCl}_{2}\right)$ at $193 \mathrm{~nm}$. Two major dissociation channels are observed: cleavage of a $\mathrm{C}-\mathrm{Cl}$ bond to form $\mathrm{CH}_{3} \mathrm{C}(\mathrm{O}) \mathrm{CHCl}+\mathrm{Cl}$ and elimination of $\mathrm{HCl}$. The branching between these reaction channels is roughly 9:1. The recoil kinetic energy distributions for both $\mathrm{C}-\mathrm{Cl}$ fission and $\mathrm{HCl}$ elimination are bimodal. The former suggests that some of the radicals are formed in an excited electronic state. A portion of the $\mathrm{CH}_{3} \mathrm{C}(\mathrm{O}) \mathrm{CHCl}$ photoproducts undergo secondary dissociation to give $\mathrm{CH}_{3}+\mathrm{C}(\mathrm{O}) \mathrm{CHCl}$. Photoelimination of $\mathrm{Cl}_{2}$ is not a significant product channel. A primary $\mathrm{C}-\mathrm{C}$ bond fission channel to give $\mathrm{CH}_{3} \mathrm{CO}+$ $\mathrm{CHCl}_{2}$ may be present, but this signal may also be due to a secondary dissociation. Data from photofragment translational spectroscopy with electron impact and photoionization detection, velocity map ion imaging, and UV-visible absorption spectroscopy are presented, along with G3//B3LYP calculations of the bond dissociation energetics.
\end{abstract}

\section{Introduction}

This paper examines, for the first time, the product channels in the photodissociation of 1,1-dichloroacetone in the $\pi \pi^{*}$ absorption band at $193 \mathrm{~nm}$. The photodissociation experiments presented here reveal primary product channels different from those previously observed for the monohalogenated acetones at $308 \mathrm{~nm}$ in the $n \pi^{*}$ absorption band. Although several halogenated acetones have important UV absorption peaks in the ultraviolet region in the range of 195 and $300 \mathrm{~nm}$, only the lower energy absorption band has been studied extensively. Studies on chloroacetone photodissociation ${ }^{1,2}$ and bromoacetone photodissociation $^{3}$ at $308 \mathrm{~nm}$ observed competing C-halogen and $\mathrm{C}-\mathrm{C}$ bond fission channels, but not hydrogen halide elimination. In contrast, the photodissociation of 1,1-dichloroacetone undergoes some branching to an $\mathrm{HCl}$ elimination channel upon $193 \mathrm{~nm}$ photodissociation. This result indicates that in modeling the role of chloroacetone and bromoacetone in atmospheric processes, ${ }^{4}$ one may need to include the wavelength dependence of the quantum yield of the primary photoproduct channels for these systems. The wavelength dependence of branching to the hydrogen halide elimination channel is yet to be established, but the current results on dichloroacetone suggest that this channel may play a more important role when the halogenated acetones absorb light via the higher energy absorption band than the one accessed at 308 nm.

Although many of the monohalogenated acetones have been investigated for their utility as simple model systems of carbonyl photochemistry and for their atmospheric importance, studies

† Present address: Department of Chemistry and AirUCI, University of California at Irvine, California 92697.

$\doteqdot$ Present address: Department of Chemistry, Yale University, New Haven, Connecticut 06520.

$\S$ Present address: Rohm \& Haas Electronic Materials, Marlborough, Massachusetts 01752 .

${ }^{\perp}$ Present address: Dept. of Biology and Chemistry, City University of Hong Kong, Kowloon, Hong Kong. elucidating the basic physical chemistry of 1,1-dichloroacetone are rather limited. Most published work on this molecule focuses on its presence in wastewater. ${ }^{5}$ Some structural information is available, including a 1954 investigation of the dipole moment, ${ }^{6}$ a paper with molecular mechanics computations on 1,1dichloroacetone, ${ }^{7}$ and one that combines LC-MO SCF HF/321G* and HF/6-31G* electronic structure calculations with IR and Raman spectroscopy. ${ }^{8}$ A more recent paper combines gasphase electron diffraction measurements with calculations at the MP2/6-311+G(d) level. ${ }^{9}$ These studies pay particular attention to characterizing torsion around the $\mathrm{HCCO}$ dihedral angle from the $(\mathrm{Cl})_{2} \mathrm{HCCO}$ portion of the molecule. Two stable conformers, the lower energy synperiplanar (also called trans) and anticlinal (also called gauche) conformations have dihedral angles of $0^{\circ}$ and $\sim 120^{\circ}$, respectively. ${ }^{9}$

Other work has examined the reactivity of 1,1-dichloroacetone. One study notes that the compound's reactivity toward hydration is enhanced in comparison to chloroacetone and acetone. ${ }^{10}$ Work by Notario et al. measures $\mathrm{Cl}$ reaction rate constants, finding that the presence of both chlorines in 1,1dichloroacetone reduces the compound's reactivity toward chlorine in comparison to both the methylated and monochlorinated analogues. ${ }^{11}$ The Notario study is of practical interest in atmospheric chemistry, as it addresses the role of atmospheric oxidation of volatile organic hydrocarbons by $\mathrm{Cl}$ in the atmosphere. For the case of 1,1-dichloroacetone, this is not likely to be a major reaction pathway; the study calculates the atmospheric lifetime of 1,1-dichloroacetone with respect to $\mathrm{Cl}$ to be on the order of 9 months.

One initial motivation for this study was to search for a photolytic precursor of the carbene radical intermediate of the $\mathrm{O}+$ propyne $\left(\mathrm{CH}_{3} \mathrm{CCH}\right)$ reaction in order to investigate the proposed role of intersystem crossing in such bimolecular reactions. Biradicals in general, and carbenes in particular, are important reaction intermediates and represent a current challenge to electronic structure theory. This reaction may be mechanistically similar to the $\mathrm{O}+$ acetylene $(\mathrm{HCCH})$ reaction 
investigated by both theoretical and experimental groups. ${ }^{12-15}$ Of particular interest is the possibility that intersystem crossing of the ketocarbene $\mathrm{HCC}(\mathrm{O}) \mathrm{H}$ intermediate in the $\mathrm{O}+\mathrm{HCCH}$ reaction $^{22,25}$ or the analogous carbene intermediate in the $\mathrm{O}+$ propyne reaction could play an important role in the product branching from the bimolecular reaction. However, this study shows that dichloroacetone is not a useful photolytic precursor for this key carbene intermediate, as it evidences competing $\mathrm{C}-\mathrm{Cl}$ bond fission and $\mathrm{HCl}$ elimination channels but not $\mathrm{Cl}_{2}$ elimination. Our results do suggest other approaches to this problem; the photolytic production of carbene intermediates via hydrogen halide elimination may be facilitated by photodissociating monohalogenated precursors at shorter wavelengths.

In this paper, we examine the photolysis of 1,1-dichloroacetone through photofragment translational spectroscopy. We present data using two complementary detection methods: electron impact ionization and tunable VUV synchrotron photoionization. With the former detection method, both a polarized and an unpolarized laser source are used. These data are complemented by state-selective $\mathrm{Cl}$ atom photofragment imaging experiments. We also report $\mathrm{ab}$ initio calculations of the endoergicities of several bond fission and molecular elimination channels energetically allowed in the photodissociation of 1,1-dichloroacetone.

\section{Experimental Section}

This work uses photofragment translational spectroscopy to measure the distribution of recoil kinetic energies imparted to products during molecular fragmentation resulting from photoexcitation. In one apparatus, situated at the University of Chicago, molecular fragments are ionized by electron bombardment. In an apparatus at the Advanced Light Source (ALS) at the Lawrence Berkeley National Laboratory, tunable vacuum ultraviolet (VUV) radiation is used for ionization. We also collected velocity map images of the spin-orbit state selected $\mathrm{Cl}$ atom photofragments.

I. Photofragment Translational Spectroscopy: Unpolarized Measurements with Electron Bombardment Detection. In this technique, a photodissociation laser beam intersects a molecular beam at a right angle. The propagation axis of the laser beam is perpendicular to the plane containing the molecular beam and the line from the interaction region to the detector. The source region containing the molecular beam nozzle rotates to allow for data collection at different source angles, defined as the angle between the molecular beam propagation axis and the line from the interaction region to the detector. Photodissociation products scatter into many angles; the apparatus samples the small portion of products with lab velocities pointed along the interaction region-to-detector line within the $1.5^{\circ}$ acceptance angle of the detector. Photolysis products travel 44.3 $\mathrm{cm}$ to the detector, where they are ionized by $200 \mathrm{eV}$ electrons, sufficient energy to ionize (and in certain cases, dissociatively ionize) virtually any neutral photofragment. The ions pass through a quadrupole mass spectrometer with a model 13 High-Q head from Extrel. The mass-selected ions are detected by a Daly detector, and the resultant voltage pulses are counted by a multichannel scaler. This gives signal proportional to the number of ions at each mass to charge ratio produced from the neutral photofragments arriving at the detector as a function of time after the dissociating light pulse. Data shown in the figures display counts versus the sum of neutral and ion flight times, and an experimentally determined ion flight constant of $\alpha=$ $4.5 \mu \mathrm{s} / \mathrm{amu}^{1 / 2}$ is used to correct for the portion of the photofragment's travel during which it is an ion.
Two types of nozzles were used to form the molecular beam. One type of molecular beam was generated from a continuous nozzle, heated to $200{ }^{\circ} \mathrm{C}$, with a $\sim 0.004$ in. diameter aperture by seeding the vapor of 1,1-dichloroacetone $(>96 \%$ purity, Aldrich) at room temperature in helium to total pressures of 2300-400 Torr (generating beams with 6-9\% 1,1-dichloroacetone). For other measurements, a General Valve solenoidactuated pulsed nozzle from Parker Hannifin Corporation was used. The pulsed nozzle has a $0.8 \mathrm{~mm}$ diameter opening and was run at $200 \mathrm{~Hz}$ and a pulse width of $300 \mu \mathrm{s}$. This heated the nozzle to temperatures between 80 and $105^{\circ} \mathrm{C}$ (finer temperature control was not possible). Total backing pressures of $\sim 700$ Torr were used with the pulsed nozzle, generating a $3 \%$ beam of 1,1-dichloroacetone in helium. Appropriate skimmers for each nozzle define the beam to $\sim 3 \mathrm{~mm}$ in diameter at the interaction region.

A $300 \mathrm{~Hz}$ chopper wheel followed by a pinhole of $0.07 \mathrm{~mm}$ diameter allowed us to measure the velocity distribution of the molecular beam; we used signal at the $m / e=43$ daughter ion. With the pulsed nozzle, the number density distribution of velocities in the molecular beam typically peaked at $1370 \mathrm{~m} / \mathrm{s}$, with a fwhm of $15.7 \%$, whereas with the continuous nozzle, it peaked at $1350 \mathrm{~m} / \mathrm{s}$ with a fwhm of $19 \%$.

The 193.3 light was produced from the ArF transition of an unpolarized PM-848 excimer laser from Lumonics. The laser was loosely focused down to a beam spot with $\sim 6 \mathrm{~mm}^{2}$ crosssectional area in the interaction region. Over the course of the experiment, laser powers ranged from 3 to $52 \mathrm{~mJ} / \mathrm{pulse}$; the exact power used for each spectrum will be noted when relevant.

II. Photofragment Translational Spectroscopy with Photoionization Detection. The photofragment translational spectroscopy apparatus formerly at Endstation 1 of the Chemical Dynamics Beamline at the ALS was used to take measurements with tunable VUV photoionization detection. The setup is similar to the one at Chicago, and a detailed description is given elsewhere. ${ }^{16}$ Relevant machine parameters include the total interaction region to detector distance of $15.1 \mathrm{~cm}$, the time-offlight constant of $7.02 \mu \mathrm{s} / \mathrm{amu}^{1 / 2}$, and the detector acceptance angle of $1.3^{\circ}$. A $2.1 \mathrm{MHz}$ Extrel quadrupole was used in all cases, which gives a resolution that varies slightly with mass. Two resolution ranges were used: "low resolution" refers to spectra for which the fwhm varied from 0.6 to 0.9 for the masses examined. "High resolution", used for the $m / e=35$ and 36 data, was higher than this but not characterized due to time constraints. At high resolution, no mass leakage from a strong signal at $m / e=35$ was detected at $m / e=34$. The machine at the Advanced Light Source utilizes piezoelectric pulsed nozzles, with nozzle diameters of either 0.5 or $1 \mathrm{~mm}$ and a pulse length of $180 \mu \mathrm{s}$. The velocity distribution of the molecular beam typically peaked at $1460 \mathrm{~m} / \mathrm{s}$, with a fwhm of $7.6 \%$. The $1,1-$ dichloroacetone was seeded in helium to typical backing pressures of 450 Torr and a $6 \%$ beam, with the nozzle heated to $65^{\circ} \mathrm{C}$.

The synchrotron radiation at the chemical dynamics beamline is generated with a U10 undulator and tuned through changes in the undulator gap. The photoionization energies, $x(\mathrm{eV})$, were determined from the undulator gap through a polynomial from a calibration done with a $3 \mathrm{~m}$ McPherson monochromator with a 600 groove/mm grating. ${ }^{17}$

$$
\begin{aligned}
& \mathrm{Gap}(\mathrm{mm})=7.875(\mathrm{~mm})+2.5054(\mathrm{~mm} / \mathrm{eV}) x- \\
& 0.0685454\left(\mathrm{~mm} / \mathrm{eV}^{2}\right) x^{2}+0.0008247\left(\mathrm{~mm} / \mathrm{eV}^{3}\right) x^{3}
\end{aligned}
$$

Beam-defining apertures were used to spatially select a portion of the ALS beam. These apertures govern the spectral bandwidth 
of the beam, giving a fwhm of $\sim 5 \%$ at the most typical setting of $10 \mathrm{~mm} \times 10 \mathrm{~mm}$. Most of the width beyond $2.3 \%$ fwhm arises from a long tail extending out to the red. ${ }^{17}$ Occasionally, a narrower spectral bandwidth was needed, so the apertures were set to $5 \mathrm{~mm} \times 5 \mathrm{~mm}$, giving $\sim 3 \%$ fwhm. In addition to radiation at the wavelength of interest, higher harmonic light is generated. An argon gas filter helps to block out these higher harmonics, and for photoionization energies below $\sim 10.8 \mathrm{eV}, \mathrm{a} \mathrm{MF}_{2}$ window was also used as a filter. In some cases, however, these filters were not sufficient, so background subtraction was used. Background was acquired by running the laser at half the repetition rate of the pulsed valve and collecting signal when the molecular beam is on and the laser is off; these data are subtracted from the normal spectra.

The $193.3 \mathrm{~nm}$ light at the ALS was obtained from the ArF transition of an unpolarized excimer laser running at a $100 \mathrm{~Hz}$ repetition rate with powers between 3 and $7 \mathrm{~mJ}$ pulse $^{-1}$ (measured outside of the chamber). An EX-50F GAM excimer laser was focused down to a beam spot with $6 \mathrm{~mm}^{2}$ crosssectional area.

III. Photofragment Translational Spectroscopy: Polarized Measurements. The angular distribution of the $\mathrm{Cl}$ fragments was determined from integrating the time-of-flight distribution of the nascent species produced by photodissociating 1,1dichloroacetone with polarized light. These measurements used the crossed laser-molecular beam apparatus at Chicago. Unpolarized laser pulses at $193.3 \mathrm{~nm}$ and $100 \mathrm{~Hz}$ were separated into two linearly polarized beams with a Spectra Physics singlecrystal quartz birefringent Pellin-Broca prism. The horizontally polarized beam was passed through a half-wave retarder to permit the angle of polarization to be varied. Before the experiments, the purity of the light and the optical axis of the half-wave retarder were verified using a second birefringent Pellin-Broca prism.

The polarized light, with powers ranging from 5 to $7 \mathrm{~mJ} /$ pulse as measured in the chamber, was focused to a $3 \mathrm{~mm}^{2}$ spot at the interaction region. The $8.8 \%$ dichloroacetone beam was seeded in helium to a total backing pressure of 300 Torr. All polarization data were taken at a nozzle temperature of $\sim 200$ ${ }^{\circ} \mathrm{C}$ and a source angle of $15^{\circ}$. Data were collected at $\mathrm{m} / \mathrm{e}=35$ for six polarization angles; a total of $3 \times 10^{5}$ shots were taken at each angle, split into six sets of 50000 shots each. The measurement order of different angles was permuted between data collection sets in order to average out drifts in molecular beam and laser intensity over time.

IV. State-Selective Detection of the Cl Atoms and Their Velocity Distributions. The imaging apparatus and laser systems used for these experiments, as well as the procedure for taking and processing imaging data (including scanning the Doppler line width and getting the total $\mathrm{C}-\mathrm{Cl}$ bond fission $P\left(E_{\mathrm{T}}\right)$ from a weighted average of the individual $\mathrm{Cl}\left({ }^{2} \mathrm{P}_{1 / 2}\right)$ and $\mathrm{Cl}\left({ }^{2} \mathrm{P}_{3 / 2}\right)$ $P\left(E_{\mathrm{T}}\right)$ 's), were identical to those described in detail previously, ${ }^{18}$ with the following exceptions. The seeded 1,1-dicloroacetone beam here was formed by bubbling helium gas through the liquid sample (partial vapor pressure of 5\%) and expanding the mixture through a pulsed valve at a stagnation pressure of $\sim 500$ Torr. The parent 1,1-dicloroacetone molecules were dissociated by a model EX10F/300 GAM excimer laser operating at the $193 \mathrm{~nm}$ ArF transition. The $\mathrm{Cl}\left({ }^{2} \mathrm{P}_{1 / 2}\right)$ and $\mathrm{Cl}\left({ }^{2} \mathrm{P}_{3 / 2}\right)$ fragments are then ionized via $[2+1]$ resonance enhanced multiphoton ionization using transitions given in the literature. ${ }^{18}$

V. Absorption Measurements. Although two absorption spectra $^{19,20}$ and a maximum absorption measurement of 1,1dichloroacetone $^{21}$ are reported in the literature, we were unable to find absorption measurements for the wavelength range investigated in this study. We recorded the absorption spectrum using a Hewlett-Packard $8453 \mathrm{UV} /$ vis spectrometer with quartz cuvettes at room temperature over the wavelength range of 190$500 \mathrm{~nm}$. Measurements were made of the vapor in the headspace above liquid 1,1-dichloroacetone. During the experiment, the spectrophotometer was flushed with house nitrogen to prevent ambient oxygen from absorbing at wavelengths near $200 \mathrm{~nm}$ and interfering with the absorption spectrum of 1,1-dichloroacetone.

VI. Calculations. Because we were unable to find literature values for most bond dissociation energies of 1,1-dichloroacetone, we computed them using Gaussian $03^{22}$ at the G3// B3LYP level of theory, as described by Baboul et al. ${ }^{23}$

VII. Summary of Masses Examined. We observed strong signal at $m / e=15,28,35,36$, and 41 , as well as a very small signal at $m / e=14$. We examined but did not see substantial signal at $m / e=16,56,42,43$, and 70 at the ALS, integrating for at least 100000 laser shots each; neither did we detect significant signal using electron bombardment detection at $m / e$ $=70$ after integrating for 3.5 million laser shots. We also looked for $m / e=111,91,90,56$, and 55 using a continuous nozzle at Chicago, but at laser powers which were above saturation. With the exception of $m / e=111$, at which there was no signal, we saw tiny signal at all of these masses, but in all cases, it appeared to be dominated by multiphoton processes. The conditions under which these data were collected are discussed in the Results Section.

\section{Results Section}

Photofragment recoil translational energy spectra clearly evidenced two primary photodissociation channels from 1,1dichloroacetone photodissociation at $193 \mathrm{~nm}$ : cleavage of a $\mathrm{C}-\mathrm{Cl}$ bond to form $\mathrm{CH}_{3} \mathrm{C}(\mathrm{O}) \mathrm{CHCl}+\mathrm{Cl}$ and elimination of $\mathrm{HCl}$ to give $\mathrm{CH}_{2} \mathrm{C}(\mathrm{O}) \mathrm{CHCl}+\mathrm{HCl}$. The branching between these two product channels is determined to be roughly $9: 1$. Two distinct $\mathrm{CH}_{3} \mathrm{C}(\mathrm{O}) \mathrm{CHCl}+\mathrm{Cl}$ product channels were observed; the channel with the lower kinetic energy distribution likely produces electronically excited radicals. Secondary dissociation of the $\mathrm{CH}_{3} \mathrm{C}(\mathrm{O}) \mathrm{CHCl}$ products from one of these channels to give $\mathrm{CH}_{3}+\mathrm{C}(\mathrm{O}) \mathrm{CHCl}$ was also detected. The data showed that photoelimination of $\mathrm{Cl}_{2}$ is not a significant product channel. A contribution to the signal at $m / e=41$ is fit to two possible options: a primary $\mathrm{C}-\mathrm{C}$ bond fission channel to form acetyl radicals $\left(\mathrm{CH}_{3} \mathrm{CO}\right)$ and $\mathrm{CHCl}_{2}$ and a secondary dissociation of a cyclic intermediate following $\mathrm{HCl}$ elimination that dissociates to give $\mathrm{HCCO}+\mathrm{CH}_{2} \mathrm{Cl}$.

We detected $\mathrm{Cl}$ atoms from the primary $\mathrm{C}-\mathrm{Cl}$ bond fission channels both at the ALS and at Chicago, and we determined the spin-orbit state selected velocity distributions in velocity map imaging experiments. Data from the ALS at $m / e=35\left(\mathrm{Cl}^{+}\right)$ are shown in Figure 1 for a photoionization energy of $15 \mathrm{eV}$ and three different source angles: $15^{\circ}, 30^{\circ}$, and $39^{\circ}$. The $P\left(E_{\mathrm{T}}\right)$ derived from forward convolution fitting of these TOF spectra is shown in Figure 2. It consists of two distributions, one ranging from 0 to $30 \mathrm{kcal} / \mathrm{mol}$ in recoil kinetic energy and the other extending from 13 to $45 \mathrm{kcal} / \mathrm{mol}$ in recoil kinetic energy. The product branching ratio of the $\mathrm{C}-\mathrm{Cl}$ bond fission channel producing high recoil kinetic energy fragments to the channel producing low recoil kinetic energy fragments, $\sigma$ (high $\mathrm{KE}$ ): $\sigma($ low KE, ) was $0.69: 0.31$, indicating that substantially more radicals are generated in the higher kinetic energy channel than in the lower kinetic energy channel. Both recoil kinetic energy distributions appear to be primary channels. We attempted to 


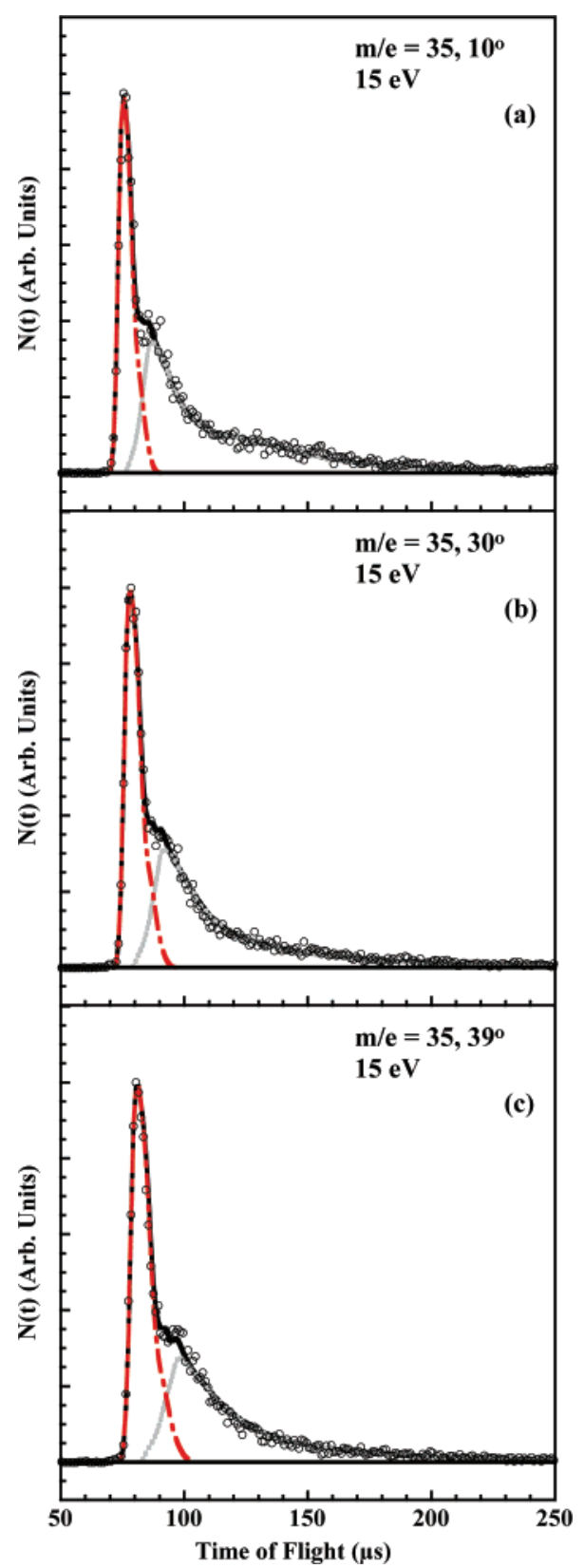

Figure 1. Background-subtracted TOF spectra at $m / e=35\left(\mathrm{Cl}^{+}\right)$, showing signal taken at a $15 \mathrm{eV}$ photoionization energy, a $65^{\circ} \mathrm{C}$ nozzle and (a) $15^{\circ}$ source angle for 20000 laser shots; (b) $30^{\circ}$ source angle for 30000 laser shots; and (c) $39^{\circ}$ source angle for 30000 laser shots. The laser power was $6 \mathrm{~mJ}$ (external to chamber), and the higher ALS resolution range was used (see the Experimental Section). We obtained the forward convolution fit to these data, given in the gray and dotteddashed lines, from the $P\left(E_{\mathrm{T}}\right)$ shown in Figure 2. Open circles show experimental data.

account for each of the distributions as secondary loss of chlorine from the radical products of other primary dissociation channels but were unable to achieve a satisfactory fit to the data in this way.

These same distributions were used to fit $m / e=35$ data taken with electron impact ionization at Chicago, as shown in Figure 3. Other contributions to the $m / e=35$ signal are detected with electron bombardment, including a contribution from dissociative ionization of $\mathrm{HCl}$ formed in a molecular elimination channel and a contribution from a secondary dissociation channel to be discussed later in this paper. The appearance energy of $\mathrm{Cl}^{+}$from $\mathrm{HCl}$ is over $17 \mathrm{eV}$, so these contributions are expected to show up in the electron impact ionization spectra but not in the spectra

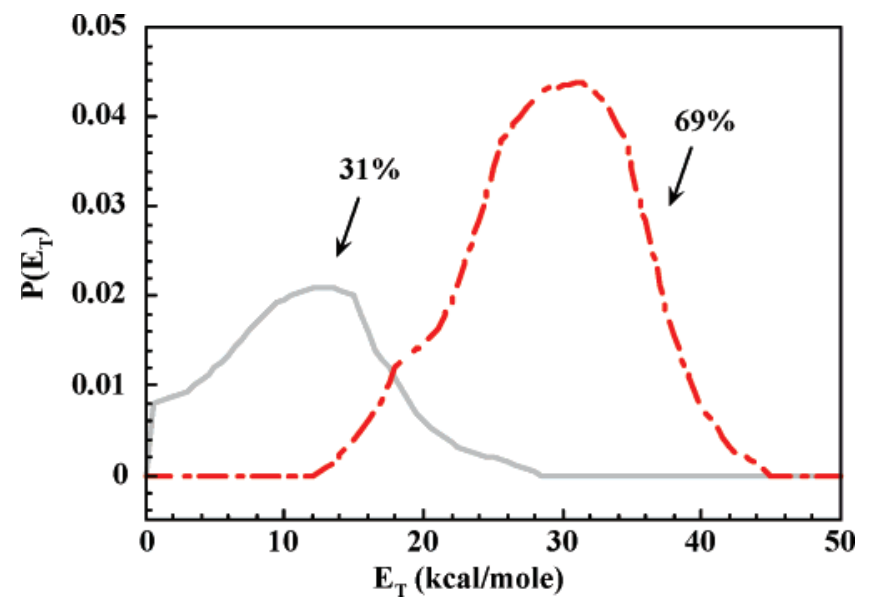

Figure 2. The $P\left(E_{\mathrm{T}}\right)$ for $\mathrm{CH}_{3} \mathrm{C}(\mathrm{O}) \mathrm{ClHC}-\mathrm{Cl}$ bond fission, derived from the forward convolution fit of the $m / e=35\left(\mathrm{Cl}^{+}\right)$spectra (Figure 1), is given by gray and dotted-dashed lines for the low and high recoil kinetic energy channels, respectively. The $P\left(E_{\mathrm{T}}\right) \mathrm{s}$ are normalized to the product channel branching, 31:69, derived from fitting the data in Figure 1.

with photoionization at $15 \mathrm{eV}$. Briefly, the latter component comes from dissociative ionization of the $\mathrm{C}(\mathrm{O}) \mathrm{CHCl}$ radical formed from secondary dissociation of the radicals formed in a portion of the high recoil kinetic energy primary $\mathrm{C}-\mathrm{Cl}$ bond fission channel. Signal arising from dissociative ionization of $\mathrm{HCl}$ from the primary $\mathrm{HCl}$ is also shown, with the branching to this process in Figure 3a calculated using the $\mathrm{Cl} / \mathrm{HCl}$ branching ratio of 0.92:0.08 determined later on and a daughter ion cracking fraction of $\mathrm{HCl}$ to $\mathrm{Cl}^{+}$of 0.1838 from the literature, ${ }^{24}$ whereas a fit with $\mathrm{Cl} / \mathrm{HCl}$ branching of 0.88:0.12 is given in Figure $3 \mathrm{~b}$ in which the daughter ion cracking fraction is determined from fitting the data at $\mathrm{HCl}^{+}$and $\mathrm{Cl}^{+}$. Previous work in our group has shown that there is reason to expect that the daughter ion cracking pattern of vibrationally excited $\mathrm{HCl}$ is not well represented by the cracking pattern of roomtemperature $\mathrm{HCl}^{25}$ Finally, there appears to be a contribution from dissociative ionization of the cofragment to $\mathrm{HCl}$ elimination in the lower kinetic energy $\mathrm{HCl}$ elimination channel. A small amount of signal centered around $173 \mu$ s appears underfit, but we were unable to account for it.

We detected tiny signal from the partner fragment to the $\mathrm{Cl}$ radical at $m / e=91\left(\mathrm{CH}_{3} \mathrm{COCHCl}^{+}\right)$with the electron bombardment apparatus, taking data for 3.75 million laser shots. Collecting appreciable signal required using laser powers approaching the saturation level of $31 \mathrm{~mJ} /$ pulse (average power was $27 \mathrm{~mJ} /$ pulse), which also produced a higher energy multiphoton signal. To our knowledge, the dissociative ionization pattern of the $\mathrm{CH}_{3} \mathrm{C}(\mathrm{O}) \mathrm{CHCl}$ radical has not been studied, but we postulate that much of the signal was lost due to fragmentation in the ionizer. For example, a portion of the signal taken at $m / e=28\left(\mathrm{CO}^{+}\right)$with VUV photoionization and shown in Figure 6 was fit by assuming that it arose from dissociative ionization of the $\mathrm{CH}_{3} \mathrm{C}(\mathrm{O}) \mathrm{CHCl}$ radical (other contributions to the $m / e=28$ data will be discussed later). In addition, evidence for products of the unimolecular dissociation of some of the radical cofragments formed from the primary $\mathrm{C}-\mathrm{Cl}$ bond fission was apparent in the $m / e=41$ spectrum to be presented later.

Preliminary measurements made via velocity map imaging with state-specific REMPI detection of $\mathrm{Cl}$, shown in Figure 4, are in qualitative agreement with the photofragment translational spectroscopy data. A contribution to the lower kinetic energy $(0-25 \mathrm{kcal} / \mathrm{mol})$ portion of the $\mathrm{Cl}\left({ }^{2} \mathrm{P}_{3 / 2}\right)$ images was not reproducible; repeated measurements suggest there is a sub- 


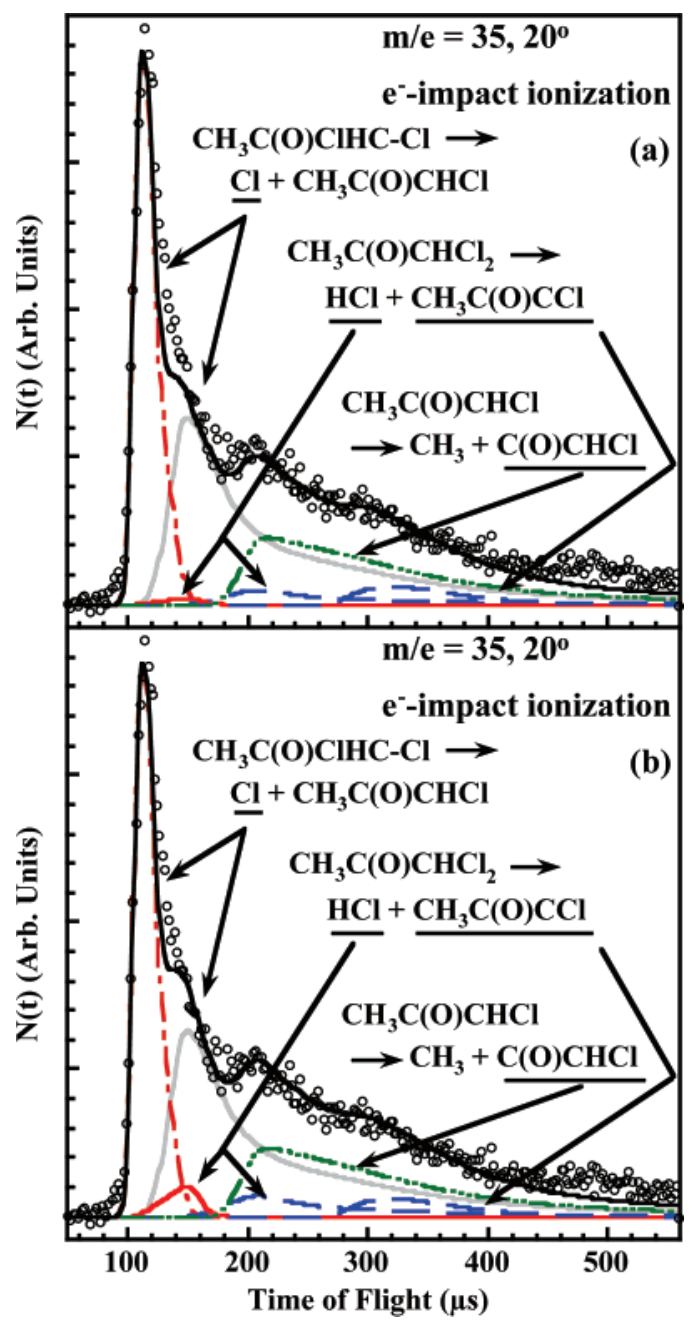

Figure 3. TOF spectrum at $m / e=35\left(\mathrm{Cl}^{+}\right)$taken at Chicago with a pulsed nozzle at $97^{\circ} \mathrm{C}$ for 1 million laser shots at a $20^{\circ}$ source angle. Mass spectrometer resolution was set to $0.6 \mathrm{amu}$ fwhm, and the laser power was $3 \mathrm{~mJ}$. Open circles show experimental data. The $P\left(E_{\mathrm{T}}\right)$ in Figure 2 is used to fit the $\mathrm{C}-\mathrm{Cl}$ fission channels with low recoil kinetic energy (gray line) and high recoil kinetic energy (dotted-dashed line). The dashed-triple-dotted line shows a contribution from the $P\left(E_{\mathrm{T}}\right)$ in Figure 12 describing how a portion of the $\mathrm{CH}_{3} \mathrm{C}(\mathrm{O}) \mathrm{CHCl}$ fragments from the high recoil kinetic energy $\mathrm{C}-\mathrm{Cl}$ fission channel undergo secondary dissociation to form $\mathrm{CH}_{3}+\mathrm{C}(\mathrm{O}) \mathrm{CHCl}$, which we assume can dissociatively ionize to $\mathrm{Cl}^{+}$. The dashed and thin solid lines show a contribution from dissociative ionization of $\mathrm{HCl}$ from the $\mathrm{HCl}$ primary elimination channel; the fit is calculated from the $P\left(E_{\mathrm{T}}\right)$ in Figure 9 . As discussed in the text, in part a, we use the 0.1838 literature daughter ion cracking fraction of $\mathrm{HCl}$ to $\mathrm{Cl}^{+}$, whereas in part $\mathrm{b}$, this parameter is determined to be 0.4365 under the assumption that the excess signal from vibrationally excited $\mathrm{HCl}$ that does not appear as $\mathrm{HCl}^{+}$shows up as $\mathrm{Cl}^{+}$. In both fits, we also include a contribution from dissociative ionization of the partner fragment to $\mathrm{HCl}$ elimination, arising from the low kinetic energy distribution from Figure 9 in a dashed line. The following product branching values were used to fit the data from the following sources, $\mathrm{Cl}$ from low kinetic energy $\mathrm{C}-\mathrm{Cl}$ fission: $\mathrm{Cl}$ from high kinetic energy $\mathrm{C}-\mathrm{Cl}$ fission: $\mathrm{HCl}$ from low kinetic energy $\mathrm{HCl}$ elimination: $\mathrm{HCl}$ from high kinetic energy $\mathrm{HCl}$ elimination: $\mathrm{CH}_{2-}$ $\mathrm{COCHCl}$ from low kinetic energy $\mathrm{HCl}$ elimination, for fit (a) 0.300 : 0.667:0.012:0.007:0.015 and for fit (b) 0.280:0.624:0.046:0.028:0.022.

stantial contribution across the $\mathrm{Cl}\left({ }^{2} \mathrm{P}_{3 / 2}\right)$ image from $\mathrm{Cl}$ atoms from the secondary photodissociation of the $\mathrm{CH}_{3} \mathrm{C}(\mathrm{O}) \mathrm{CHCl}$ radical products by the REMPI probe laser. The images in Figure 4 show the spectra for which that contribution was minimized. Figure 5 shows the recoil kinetic energy distributions, derived from the data in Figure 4, for $\mathrm{C}-\mathrm{Cl}$ bond fission producing ground $\left({ }^{2} \mathrm{P}_{3 / 2}\right)$ and spin-orbit excited $\left({ }^{2} \mathrm{P}_{1 / 2}\right) \mathrm{Cl}$ atoms. Also
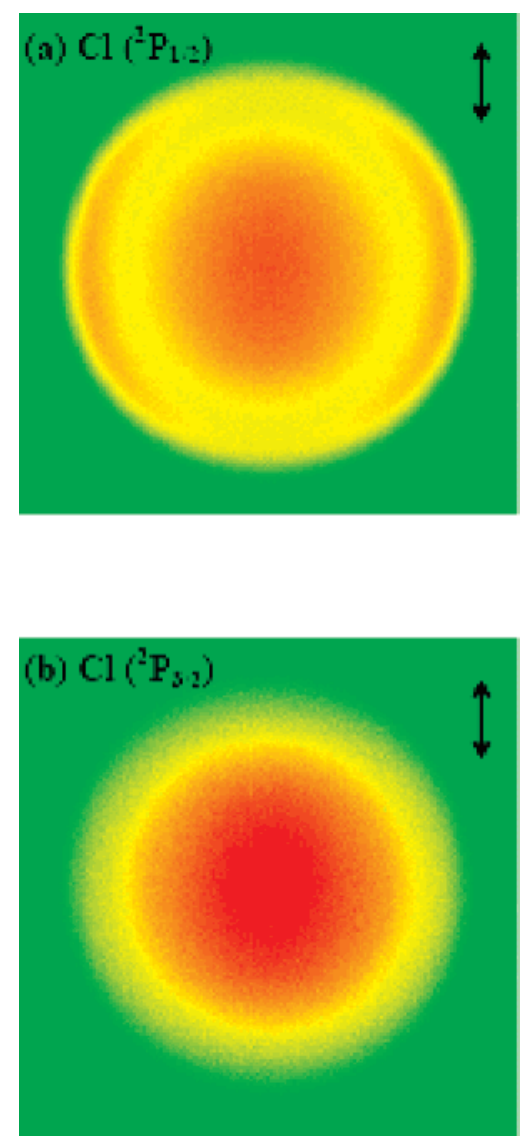

Figure 4. Velocity map ion images of (a) $\mathrm{Cl}\left({ }^{2} \mathrm{P}_{1 / 2}\right)$ and (b) $\mathrm{Cl}\left({ }^{2} \mathrm{P}_{3 / 2}\right)$ photofragments from $\mathrm{C}-\mathrm{Cl}$ bond fission of 1,1-dichloroacetone obtained at $193+235 \mathrm{~nm}$. The laser polarization is along the vertical direction in the plane of the images. Each image consists of $861 \times$ 861 pixels.

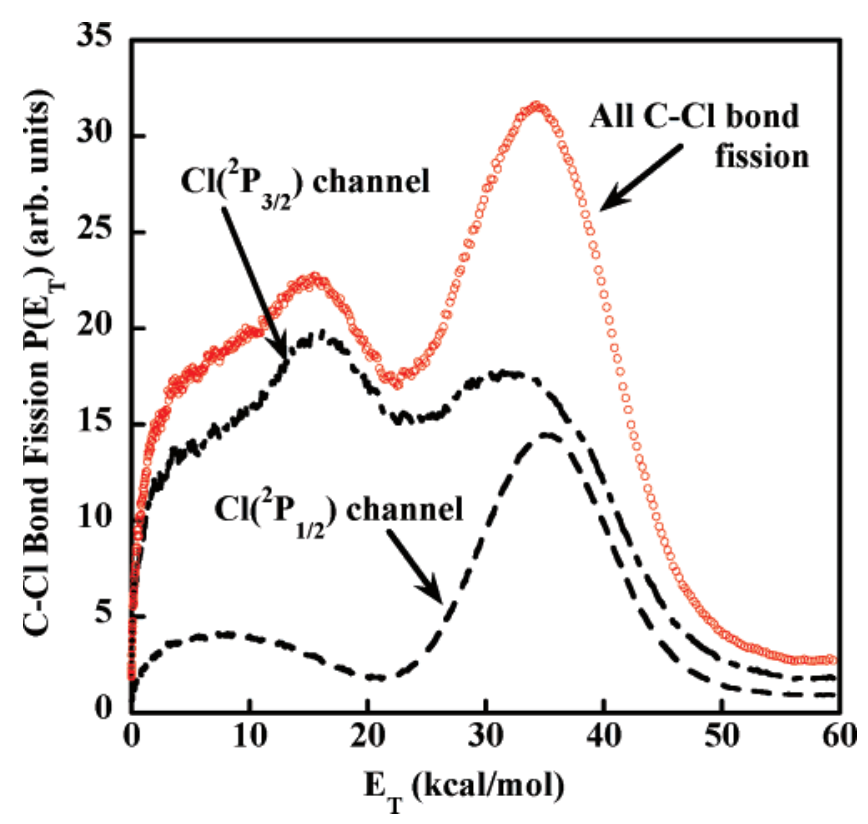

Figure 5. $\mathrm{C}-\mathrm{Cl}$ bond fission recoil kinetic energy distributions derived from the images shown in Figure 4. The total $\mathrm{C}-\mathrm{Cl}$ bond fission $P\left(E_{\mathrm{T}}\right)$ is constructed from a weighted average of the distributions from the channels producing $\mathrm{Cl}\left({ }^{2} \mathrm{P}_{3 / 2}\right)$ and $\mathrm{Cl}\left({ }^{2} \mathrm{P}_{1 / 2}\right)$ using the spin-orbit branching fractions derived from the integrated signals at each and weighting those with a literature REMPI line strength ratio. ${ }^{26}$

shown in Figure 5 is the total $P\left(E_{\mathrm{T}}\right)$ for $\mathrm{C}-\mathrm{Cl}$ fission derived from the imaging data. To construct this, we weighted the integrated signal at $\mathrm{Cl}\left({ }^{2} \mathrm{P}_{3 / 2}\right)$ and $\mathrm{Cl}\left({ }^{2} \mathrm{P}_{1 / 2}\right)$ by the REMPI line 


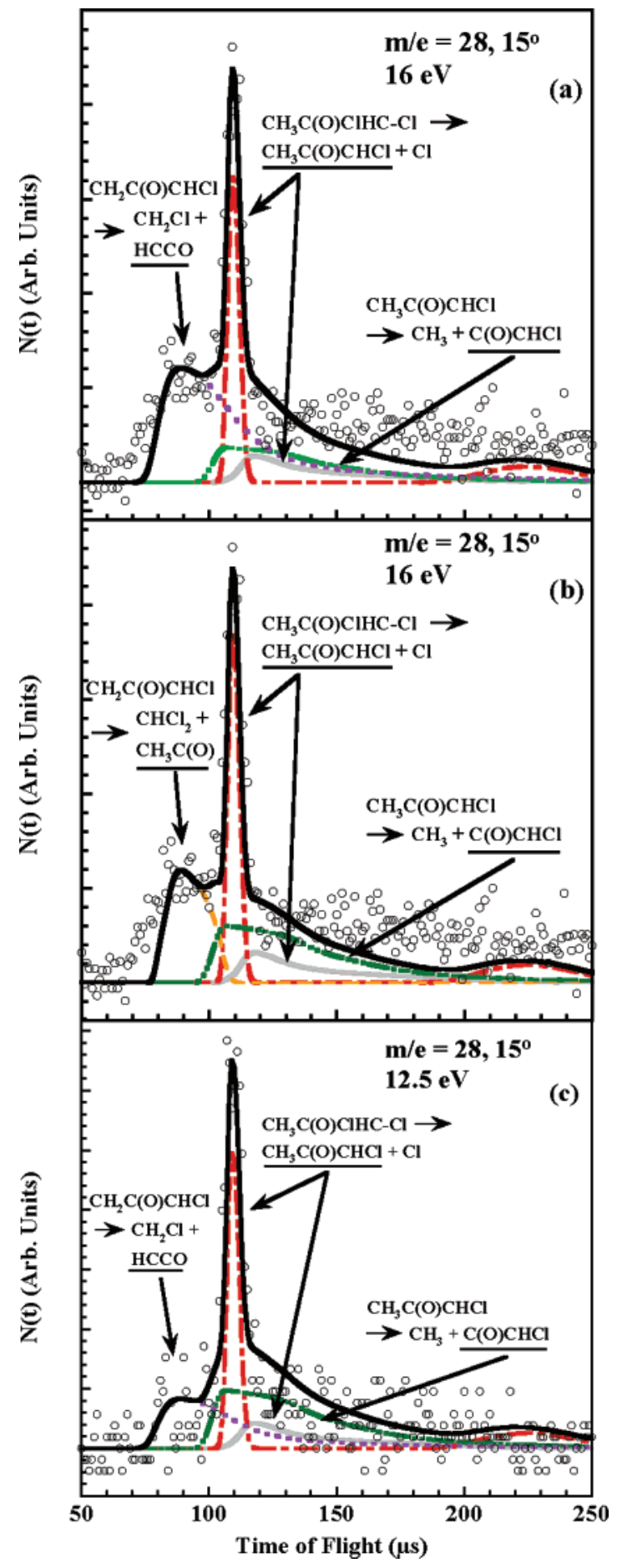

Figure 6. TOF spectra at $m / e=28\left(\mathrm{CO}^{+}\right)$taken at the ALS with a 65 ${ }^{\circ} \mathrm{C}$ nozzle, a source angle of $15^{\circ}$, and photoionization energies of (a, b) $16 \mathrm{eV}$ and (c) $12.5 \mathrm{eV}$. The laser power was $3 \mathrm{~mJ}$ (external to chamber), and the lower ALS resolution range was used (see the Experimental Section). The fit includes dissociative ionization contributions from both $\mathrm{C}-\mathrm{Cl}$ fission channels given in the $P\left(E_{\mathrm{T}}\right)$ in Figure 2, although the higher $E_{\mathrm{T}}$ channel only shows up for the low $E_{\mathrm{T}}$, high $E_{\text {int }}$ range. The dashed-triple-dotted line shows a contribution from the $P\left(E_{\mathrm{T}}\right)$ in Figure 11 describing how a portion of the $\mathrm{CH}_{3} \mathrm{C}(\mathrm{O}) \mathrm{CHCl}$ fragments from the high recoil kinetic energy $\mathrm{C}-\mathrm{Cl}$ fission channel undergo secondary dissociation to form $\mathrm{CH}_{3}+\mathrm{C}(\mathrm{O}) \mathrm{CHCl}$, which we assume can dissociatively ionize to $\mathrm{CO}^{+}$. The dotted lines in fits a and c show a secondary dissociation following $\mathrm{HCl}$ elimination, in which a cyclic intermediate dissociates to form $\mathrm{HCCO}+\mathrm{CH}_{2} \mathrm{Cl}$, as described by the $P\left(E_{\mathrm{T}}\right)$ in Figure 13 . The alternate fit in b to the $16 \mathrm{eV}$ photoionization data shows a contribution from the postulated primary channel described by the $P\left(E_{\mathrm{T}}\right)$ in Figure 15 in which $\mathrm{C}-\mathrm{C}$ fission gives $\mathrm{CH}_{3} \mathrm{C}(\mathrm{O})+\mathrm{CHCl}_{2}$ in a thin, dashed line.

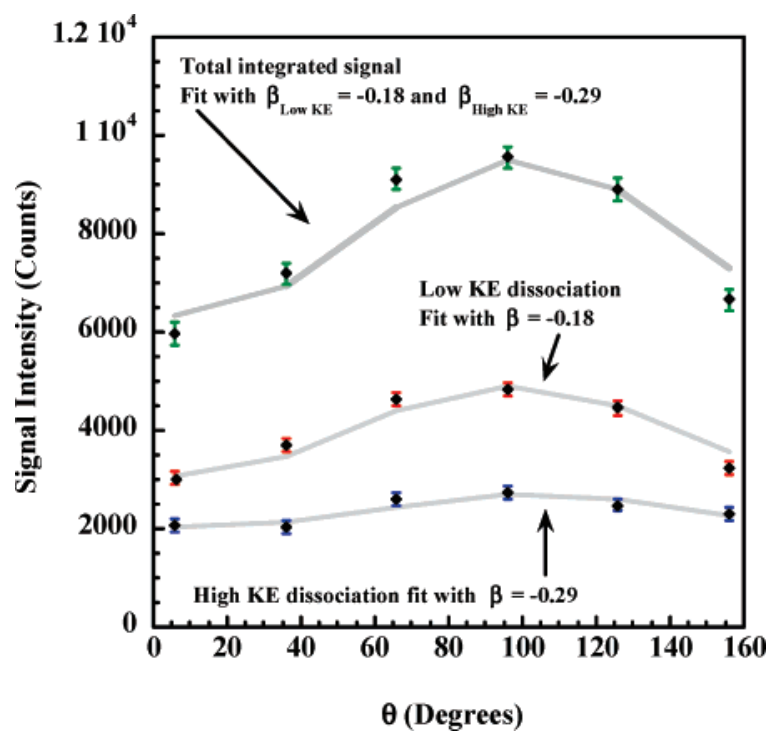

Figure 7. The average anisotropy of the two $\mathrm{C}-\mathrm{Cl}$ fission channels given in the $P\left(E_{\mathrm{T}}\right)$ in Figure 2. Diamonds represent integrated signal at $m / e=35\left(\mathrm{Cl}^{+}\right)$integrated over 300000 laser shots for several polarizations of the photolytic laser beam. Data were taken with electron impact ionization, a source angle of $15^{\circ}$, and laser powers of 5-7 mJ. As noted on the graph, signal is integrated for ranges including predominantly the low recoil kinetic energy $(182-212 \mu \mathrm{s})$, the high recoil kinetic energy range $(130-160 \mu \mathrm{s})$, and a range covering contributions from both channels $(130-212 \mu \mathrm{s})$. The best fit to these experimental points is given with $\beta_{\text {Low KE }}=-0.18$ and $\beta_{\mathrm{High} \mathrm{KE}}=-0.29$, as shown on the graph for the signal from the high and low recoil kinetic energy ranges as well as the total signal.

strength factor determined by Liyanage et al., ${ }^{26}$ thus determining the product branching to be roughly $71 \% \mathrm{Cl}\left({ }^{2} \mathrm{P}_{3 / 2}\right)$ and $29 \%$ $\mathrm{Cl}\left({ }^{2} \mathrm{P}_{1 / 2}\right)$. We then added the two state-selected $P\left(E_{\mathrm{T}}\right)$ s derived from the data in Figure 4, weighted by that branching ratio. The contamination at low energies in the $\mathrm{Cl}\left({ }^{2} \mathrm{P}_{3 / 2}\right)$ data results in the total $P\left(E_{\mathrm{T}}\right)$ having a lower energy component that is too large. With that exception, the total $P\left(E_{\mathrm{T}}\right)$ in Figure 5 is qualitatively similar to that in Figure 2 from the non-stateselective experiments. The only firm conclusion that can be drawn from the imaging data is that the low kinetic energy release $\mathrm{C}-\mathrm{Cl}$ bond fission channel produces primarily $\mathrm{Cl}$ atoms in the ground spin-orbit state, whereas the high kinetic energy release $\mathrm{C}-\mathrm{Cl}$ bond fission channel produces both $\mathrm{Cl}\left({ }^{2} \mathrm{P}_{3 / 2}\right)$ and $\mathrm{Cl}\left({ }^{2} \mathrm{P}_{1 / 2}\right)$.

The anisotropy parameters that fit the data change significantly with recoil velocity, even within the high recoil kinetic energy distribution. Near the peak of the $P\left(E_{\mathrm{T}}\right)$ for producing $\mathrm{Cl}^{*}$ fragments, the best fit $\beta$ parameter is approximately -0.2 . Extracting the anisotropy parameters that characterize the $\mathrm{C}-\mathrm{Cl}$ bond fission processes that form ground spin-orbit state $\mathrm{Cl}$ atoms is not possible. We characterized the anisotropy of the total chlorine signal (including both ground and excited-state chlorine) via photofragment translational spectroscopy, as described below.

We measured the angular distribution of the products at $m / e$ $=35$ using polarized laser light as described in the Experimental Section; the results are shown in Figure 7. The TOF spectra from photodissociation with polarized laser light were integrated over the $130-212 \mu$ s range corresponding to the primary photodissociation signal, as seen in Figure 3. Separate integrations for the signal from the high translational energy $\mathrm{C}-\mathrm{Cl}$ bond fission channel from 130 to $160 \mu \mathrm{s}$ and the signal from the low translational energy $\mathrm{C}-\mathrm{Cl}$ bond fission channel from 


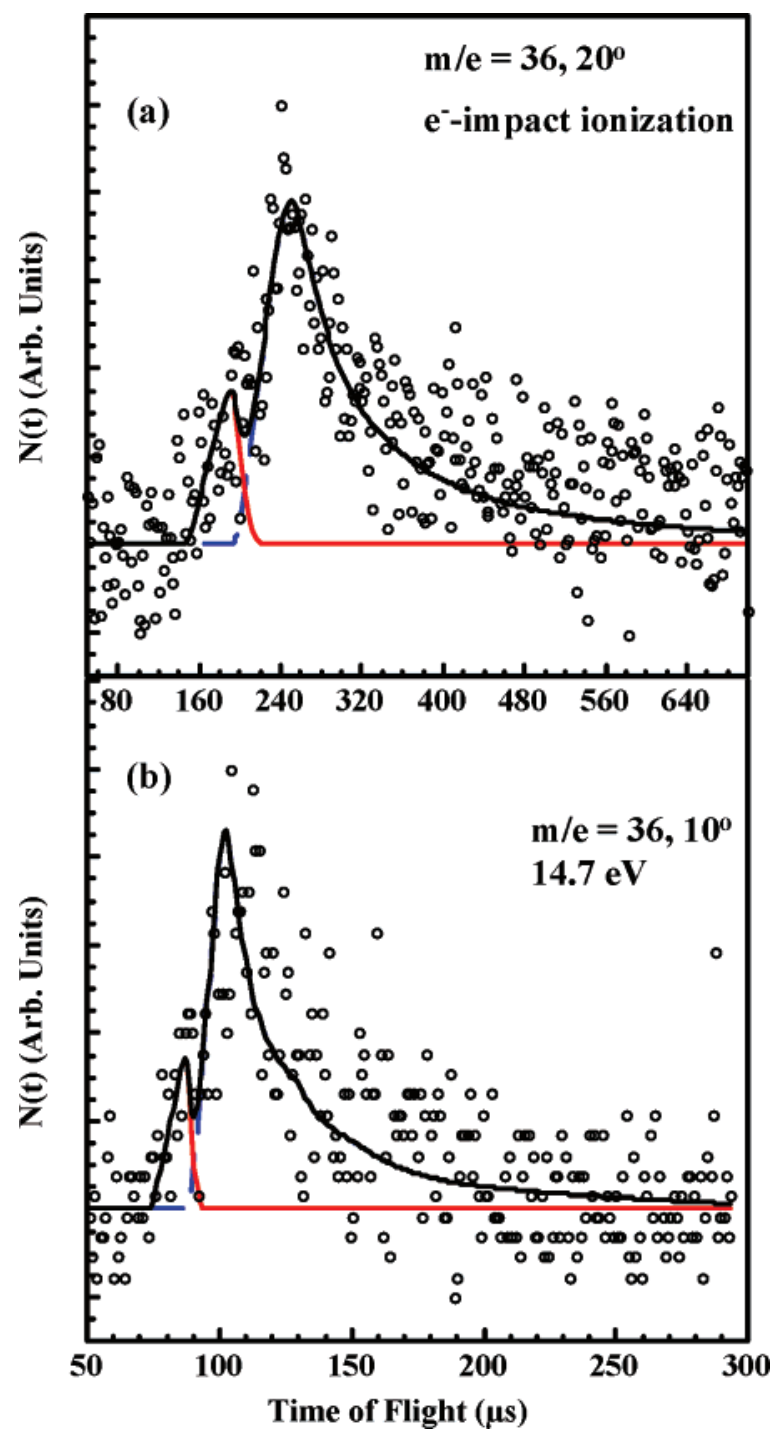

Figure 8. TOF spectra at $m / e=36\left(\mathrm{HCl}^{+}\right)$. (a) Signal was taken with a pulsed nozzle at $97^{\circ} \mathrm{C}$, a source angle of $20^{\circ}$, an average laser power of $3 \mathrm{~mJ}$, and $0.6 \mathrm{amu}$ fwhm resolution at Chicago for 1 million laser shots. (b) Background-subtracted signal taken at a $10^{\circ}$ source angle, $14.7 \mathrm{eV}$ photoionization energy, and $6.5 \mathrm{~mJ}$ (external, lower power) for 150000 laser shots at the ALS. The higher ALS resolution range was used (see the Experimental Section). We obtained the forward convolution fit to these data, shown in the thin solid and dashed lines, from the $P\left(E_{\mathrm{T}}\right)$ shown in Figure 9. Open circles show experimental data.

182 to $212 \mu$ s were also performed so that the anisotropy parameter for each channel could be determined individually.

The classical electric dipole equation is given in eq 2 , where $\theta_{\mathrm{cm}}$ is the angle between the electric vector of the linearly polarized light and the fragments' recoil direction in the center of mass reference frame. This relation was used to characterize the angular distribution of the $\mathrm{Cl}$ radicals measured in our experiments and to determine the anisotropy parameter $\beta$, as described in the 1972 monograph by Zare. ${ }^{27}$

$$
I\left(\theta_{\mathrm{cm}}\right)=\frac{1}{4 \pi}\left[1+\beta P_{2}\left(\cos \theta_{\mathrm{cm}}\right)\right]
$$

Here, $P_{2}$ is the Legendre polynomial of degree 2. A forward convolution fitting procedure using the $P\left(E_{\mathrm{T}}\right)$ s in Figure 2 was used to determine the anisotropy parameter for the angular distribution of the $\mathrm{Cl}$ atoms. This involved varying the value of $\beta$ while taking into account the molecular beam velocity

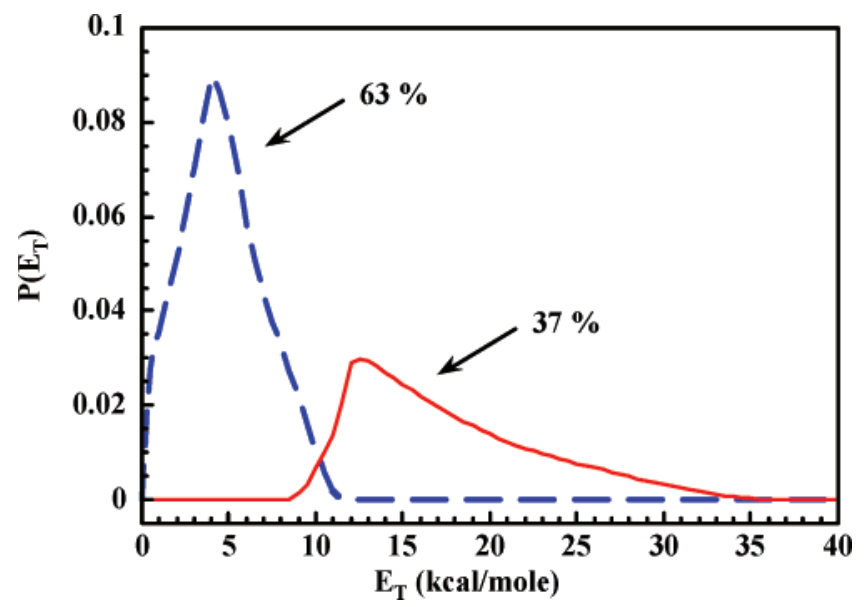

Figure 9. The $P\left(E_{\mathrm{T}}\right)$ for molecular elimination yielding $\mathrm{HCl}+\mathrm{CH}_{2} \mathrm{C}$ (O) $\mathrm{CHCl}$ (or $\mathrm{CH}_{3} \mathrm{C}(\mathrm{O}) \mathrm{CCl}$ ), derived from the forward convolution fit of the $m / e=36\left(\mathrm{HCl}^{+}\right)$spectra in Figure 8, is resolved into low recoil kinetic energy (dashed line) and high recoil kinetic energy (thin solid line) portions. The components are normalized to the product channel branching, 63:37.

distribution, source-detector angle, and the appropriate kinematic factors. The high kinetic energy $\mathrm{C}-\mathrm{Cl}$ bond fission channel was best fit by an anisotropy parameter of $\beta=-0.29$ with a $95 \%$ confidence interval from $\beta=-0.35$ to $\beta=-0.23$. The low kinetic energy $\mathrm{C}-\mathrm{Cl}$ cleavage channel was best fit by an anisotropy parameter of $\beta=-0.18$ with a broader $95 \%$ confidence interval extending from $\beta=-0.29$ to $\beta=-0.07$. The variation in the best fit $\beta$ was calculated using Fieller's method. ${ }^{28}$ The fits generated by these values are given in Figure 7.

In addition to the two carbon-chlorine bond fission channels, an $\mathrm{HCl}$ elimination channel to form $\mathrm{HCl}+\mathrm{CH}_{3} \mathrm{C}(\mathrm{O}) \mathrm{CCl}$ or $\mathrm{HCl}+\mathrm{CH}_{2} \mathrm{C}(\mathrm{O}) \mathrm{CClH}$ was also detected in the data using both electron impact and photoionization detection. Data taken at $m / e=36\left(\mathrm{HCl}^{+}\right)$are shown in Figure 8, and the two-component $P\left(E_{\mathrm{T}}\right)$ derived from the fit to these data is given in Figure 9. The $P\left(E_{\mathrm{T}}\right)$ describing the elimination channel has one component from 0 to $11 \mathrm{kcal} / \mathrm{mol}$ in recoil kinetic energy with a sharp peak near $5 \mathrm{kcal} / \mathrm{mol}$ and a second component with a peak at $13 \mathrm{kcal} /$ mol. This component begins at $9 \mathrm{kcal} / \mathrm{mol}$ and extends to 36 $\mathrm{kcal} / \mathrm{mol}$. Signal at long times is attributed to residual background from the pulsed beam. We looked for the cofragment to $\mathrm{HCl}$ at $m / e=90$ with electron impact ionization, integrating for 2 million laser shots. As in the case for $m / e=91$, only tiny signal was observed, and it appears to be dominated by multiphoton effects; $22 \mathrm{~mJ} /$ pulse laser power needed to detect signal was $\sim 70 \%$ of the saturation level.

The branching between the $\mathrm{C}-\mathrm{Cl}$ bond fission and the $\mathrm{HCl}$ elimination channels was determined by taking a series of data, alternating between $m / e=35$ and $m / e=36$, with the apparatus using electron bombardment detection. Data at each mass were taken in five sets of 200000 shots each for a total of 1 million laser shots at each mass, at a laser power of $3 \mathrm{~mJ} / \mathrm{pulse}$. We integrated the signal in the $\mathrm{Cl}^{+}$spectrum from 132 to $200 \mu \mathrm{s}$ and the signal in the $\mathrm{HCl}$ spectrum at $m / e=36$ from 152 to $300 \mu \mathrm{s}$. We corrected this signal ratio by the expected signal at these masses using the $P\left(E_{\mathrm{T}}\right) \mathrm{s}$ in Figures 2 and 9, thus accounting for the appropriate kinematic factors and transit time through the ionizer. In order to make a direct comparison with the expected signal, the integrated signal is reduced to the percentage of signal that the primary distribution $P\left(E_{\mathrm{T}}\right)$ fits, excluding signal that we attribute to secondary dissociation and dissociative ionization (a substantial fraction of the electron 
impact signal at $m / e=35$ ). Using eq 3 below, we incorporate an estimate of the electron bombardment ionization cross sections and use the literature electron-bombardment fragmentation pattern of $\mathrm{HCl}$ to arrive at our best estimate for the $\mathrm{C}-\mathrm{Cl}$ fission: a $\mathrm{HCl}$ elimination product branching ratio of 0.92:0.08.

$$
\begin{aligned}
& R=\frac{\sigma_{\mathrm{C}-\mathrm{Cl} \text { fission }}}{\sigma_{\mathrm{HCl} \mathrm{elim}}} \\
& =\left(\frac{\sigma_{\text {ion }}(\mathrm{HCl})}{\sigma_{\text {ion }}(\mathrm{Cl})}\right)\left(\frac{f_{\mathrm{HCl}^{+}} / \mathrm{HCl}}{f_{\mathrm{Cl}^{+}} / \mathrm{Cl}}\right)\left(\frac{\text { expected sig } \mathrm{HCl}}{\mathrm{HCl}^{+} \text {signal }}\right) \\
& {\left[\frac{\mathrm{Cl}^{+} \operatorname{sig}_{\text {highKE }}}{\left(\text { expected sig } \mathrm{Cl}_{\text {high KE }}\right)\left(1+\frac{\beta_{\mathrm{Cl} \mathrm{high}}}{4}\right)}+\right.} \\
& \left.\frac{\mathrm{Cl}^{+} \operatorname{sig}_{\text {low KE }}}{\left(\text { expected sig } \mathrm{Cl}_{\text {low KE }}\right)\left(1+\frac{\beta_{\mathrm{Cl} \text { low }}}{4}\right)}\right] \\
& R=\frac{\sigma_{\mathrm{C}-\mathrm{Cl} \text { fission }}}{\sigma_{\mathrm{HCl} \mathrm{elim}}}=\frac{42.74}{35.15} \times \frac{0.6127}{1} \times\left(\frac{0.01813}{7390}\right) \\
& {\left[\frac{25,725}{(0.005944)(0.9725)}+\frac{10,095}{(0.005279)(0.955)}\right]=12.2}
\end{aligned}
$$

The ionization cross sections, $\sigma$, for $\mathrm{Cl}$ and $\mathrm{HCl}$ are estimated to $\pm 20 \%$ using the empirical relationship suggested by Center and $\mathrm{Mandl}^{29}$ between the molecular polarizability and the electron bombardment ionization cross section. We estimate the fraction of $\mathrm{HCl}$ appearing at $\mathrm{HCl}^{+}$as $\mathrm{fHCl}^{+} / \mathrm{HCl}=0.6127$ from data in the literature for cold $\mathrm{HCl}^{24}$ We assume $\beta=0$ for the $\mathrm{HCl}$ elimination channel, and we use $\beta_{\text {high KE }}=-0.29$ and $\beta_{\text {low KE }}=-0.18$ for the $\mathrm{C}-\mathrm{Cl}$ elimination channel as determined by our experiments with polarized light.

By far, the dominant uncertainty in determining the branching is the combination of the total ionization cross section of $\mathrm{Cl}$ as compared to $\mathrm{HCl}$ and the daughter ion cracking pattern of $\mathrm{HCl}$. Previous work in our group found that vibrationally excited $\mathrm{HCl}$ from molecular elimination exhibited a daughter ion fragmentation pattern different from that of room-temperature $\mathrm{HCl} .{ }^{25} \mathrm{We}$ provide a limiting estimate for the $\mathrm{C}-\mathrm{Cl}$ fission: a $\mathrm{HCl}$ elimination product branching ratio of 0.88:0.12 that assumes that vibrationally hot $\mathrm{HCl}$ has enhanced fragmentation to $\mathrm{Cl}^{+}$, to a degree determined by the fit to our data given in Figure 3b. For this estimate, we compare signal attributed to $\mathrm{HCl}$ that appears at $m / e=35$ and $m / e=36$ in order to estimate the daughter ion fragmentation pattern of $\mathrm{HCl}$.

We detected strong signal at $m / e=15\left(\mathrm{CH}_{3}{ }^{+}\right)$, shown in Figure 10, in which two distinct distributions could be detected through variation of the energy used for photoionization. The bulk of the signal changed very little when the photoionization energy was changed from 13 to $11.8 \mathrm{eV}$, but a small sharp peak near $80 \mu \mathrm{s}$ (at a $15^{\circ}$ source angle) varied with the photoionization energy. Most of the signal in the $m / e=15$ data was well fit by assuming that a portion of the $\mathrm{CH}_{3} \mathrm{C}(\mathrm{O}) \mathrm{CHCl}$ resulting from the high kinetic energy $\mathrm{Cl}$ loss channel underwent secondary dissociation to $\mathrm{CH}_{3}+\mathrm{C}(\mathrm{O}) \mathrm{CHCl}$. The distribution of recoil kinetic energies in this unimolecular dissociation was obtained from forward-convolution fitting of the spectrum in Figure 10; the $P\left(E_{\mathrm{T}}\right)$ that gave the best fit is given in Figure 11. In calculating these fits, we assumed that only the highest internal energy $\mathrm{CH}_{3} \mathrm{C}(\mathrm{O}) \mathrm{CHCl}$ radicals formed in the high kinetic energy $\mathrm{C}-\mathrm{Cl}$ bond fission channel underwent this secondary dissociation. Thus, we used only the portion of the

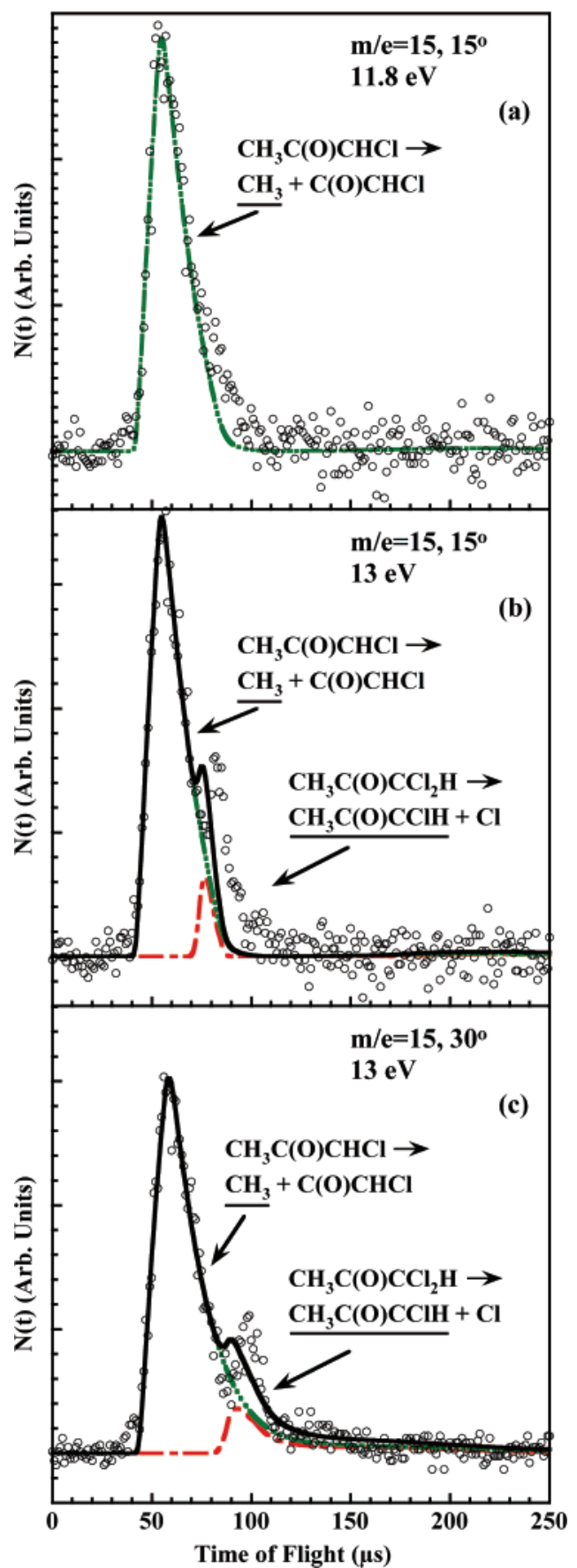

Figure 10. Background-subtracted $m / e=15\left(\mathrm{CH}_{3}{ }^{+}\right)$TOF spectra from the ALS, each averaged over 100000 shots and taken at (a) $15^{\circ}$ source angle and $11.8 \mathrm{eV}$ photoionization energy, (b) $15^{\circ}$ source angle and $13 \mathrm{eV}$ photoionization energy, (c) $30^{\circ}$ source angle and 13 $\mathrm{eV}$ photoionization energy. The laser power was 5-6 mJ (external to chamber) and the lower ALS resolution range was used (see the Experimental Section). The forward convolution fit to these data, shown with dashed-triple-dotted lines, corresponds to secondary dissociation of $\mathrm{CH}_{3} \mathrm{C}(\mathrm{O}) \mathrm{CHCl}$ to give $\mathrm{CH}_{3}+\mathrm{C}(\mathrm{O}) \mathrm{CHCl}$. The primary $P\left(E_{\mathrm{T}}\right)$ was the portion of the distribution shown in dotted-dashed lines in Figure 2 ranging from 13 to $19 \mathrm{kcal} / \mathrm{mol}$. The $P\left(E_{\mathrm{T}}\right)$ for secondary dissociation is given in Figure 11. The fit shown in the dotted-dashed line for the small peak in $b$ and $c$ assumes that the stable portion of the $\mathrm{CH}_{3} \mathrm{C}(\mathrm{O}) \mathrm{CHCl}$ photofragments formed in the high kinetic energy release $\mathrm{C}-\mathrm{Cl}$ bond fission channel from Figure 2 undergo dissociative ionization to $\mathrm{CH}_{3}{ }^{+}$. Open circles show experimental data.

$\mathrm{CH}_{3} \mathrm{C}(\mathrm{O}) \mathrm{CHCl}$ photofragments formed in primary $\mathrm{C}-\mathrm{Cl}$ bond fission events that partitioned between 13 and $17 \mathrm{kcal} / \mathrm{mol}$ of translational energy to represent those that undergo secondary 


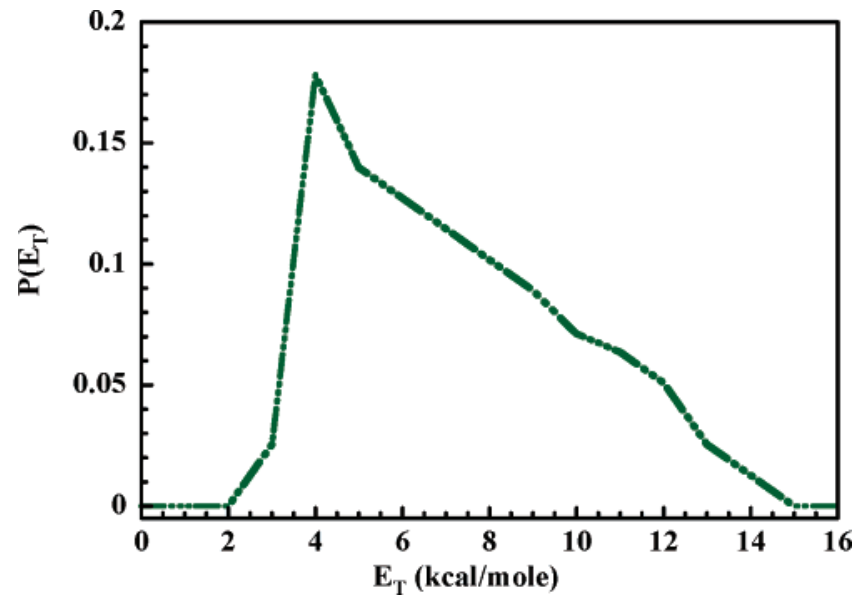

Figure 11. The $P\left(E_{\mathrm{T}}\right)$ for secondary dissociation of $\mathrm{CH}_{3} \mathrm{C}(\mathrm{O}) \mathrm{CHCl}$ to give $\mathrm{CH}_{3}+\mathrm{C}(\mathrm{O}) \mathrm{CHCl}$, derived from fitting the $m / e=15\left(\mathrm{CH}_{3}{ }^{+}\right)$data shown in Figure 10, is given in the dashed-triple-dotted line. The $\mathrm{CH}_{3} \mathrm{C}(\mathrm{O}) \mathrm{CHCl}$ fragments that undergo this dissociation arise from the portion of the high recoil kinetic energy $\mathrm{C}-\mathrm{Cl}$ fission $P\left(E_{\mathrm{T}}\right)$ given in Figure 2 that have recoil kinetic energies between 13 and $17 \mathrm{kcal} / \mathrm{mol}$. This $P\left(E_{\mathrm{T}}\right)$ also fits a daughter ion of the momentum-matched $\mathrm{C}(\mathrm{O})$ $\mathrm{CHCl}$ cofragment detected at $m / e=41$, as shown in Figure 12, and is a component of the fit to the $m / e=35$ data collected with electron impact ionization (Figure 3).

dissociation at the $\mathrm{C}-\mathrm{C}$ bond. Due to time constraints, we did not look for signal at the partner mass of $m / e=76\left(\mathrm{COCHCl}^{+}\right)$, but the secondary $P\left(E_{\mathrm{T}}\right)$ also gives a good fit for signal at $\mathrm{m} / \mathrm{e}$ $=41$, which would be generated from the dissociative ionization of this fragment (Figure 12). It also fits the long, slow tail observed in the $m / e=35$ data taken with electron impact ionization in Figure 3. We note that the same $m / e=15$ signal could also be well fit assuming a reaction channel with $\mathrm{C}-\mathrm{C}$ bond cleavage of the parent molecule $\mathrm{CH}_{3} \mathrm{C}(\mathrm{O}) \mathrm{CHCl}_{2}$ to give $\mathrm{CH}_{3}$ and $\mathrm{C}(\mathrm{O}) \mathrm{CHCl}_{2}$. The $m / e=41$ signal can alternately be satisfactorily fit as dissociative ionization of the $\mathrm{Cl}$ and $\mathrm{HCl}$ cofragments, although the resulting fit is not as good as the one that assumes secondary dissociation of $\mathrm{CH}_{3} \mathrm{C}(\mathrm{O}) \mathrm{CHCl}$. We looked for signal at the cofragment mass, m/e $=111(\mathrm{CO}-$ $\mathrm{CHCl}_{2}{ }^{+}$), to methyl loss but did not see signal after 2 million laser shots at high power $(50 \mathrm{~mJ} /$ pulse $)$.

The second peak in the $m / e=15\left(\mathrm{CH}_{3}{ }^{+}\right)$data, which is quite low in energy and narrow, is not easily assigned. We show the predicted arrival times of the $\mathrm{CH}_{3}{ }^{+}$daughter ions that would be formed from the stable portion of the $\mathrm{CH}_{3} \mathrm{C}(\mathrm{O}) \mathrm{CHCl}$ photofragments formed in the high kinetic energy release $\mathrm{C}-\mathrm{Cl}$ bond fission channel in the dotted-dashed line in Figure 10. However, the arrival time for the actual peak is later than the signal expected from this source at $15^{\circ}$. Because no fragment velocity distribution was able to fit the slow peak correctly at both $15^{\circ}$ and $30^{\circ}$, we suspect that there may have been variation in the beam velocity between these scans, although there is no other indication of such a problem.

The major remaining photofragment signal to be accounted for is the signal detected at $m / e=41$ shown in Figure 12. All the signal with arrival times longer than $100 \mu \mathrm{s}$ is well fit by the same $P\left(E_{\mathrm{T}}\right)$, Figure 11 , that was used to fit the methyl products from the unimolecular dissociation of a portion of the $\mathrm{CH}_{3} \mathrm{C}(\mathrm{O}) \mathrm{CHCl}$ cofragments formed in primary $\mathrm{C}-\mathrm{Cl}$ bond fission. Those vibrationally excited photofragments undergo secondary dissociation to $\mathrm{CH}_{3}+\mathrm{C}(\mathrm{O}) \mathrm{CHCl}$; the $\mathrm{C}(\mathrm{O}) \mathrm{CHCl}$ products are dissociatively ionized at $11.3 \mathrm{eV}$ to $\mathrm{COCH}^{+}$. The fast peak in the $m / e=41$ spectrum is difficult to assign, and we present two possibilities here. The arrival times are far too

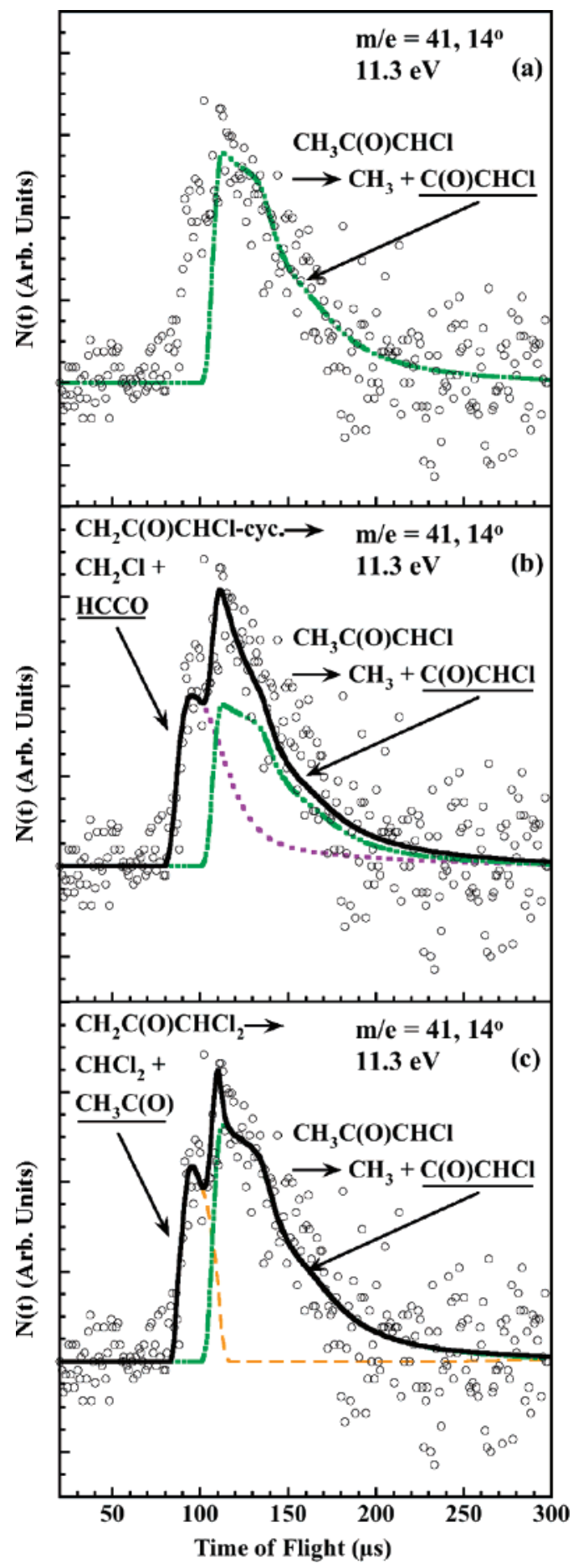

Figure 12. Background-subtracted $m / e=41\left(\mathrm{C}(\mathrm{O}) \mathrm{CH}^{+}\right)$TOF spectra from the ALS, averaged over 300000 shots and taken at a $14^{\circ}$ source angle with $11.3 \mathrm{eV}$ photoionization energy. The laser power was $6 \mathrm{~mJ}$ (external to chamber), and the lower ALS resolution range was used (see the Experimental Section). (a) The fit shown in the dashed-tripledotted lines shows the contribution from the $m / e=41$ daughter ion of the $\mathrm{C}(\mathrm{O}) \mathrm{CHCl}$ product from the secondary dissociation of $\mathrm{CH}_{3} \mathrm{C}(\mathrm{O})$ $\mathrm{CHCl}$ to give $\mathrm{CH}_{3}+\mathrm{C}(\mathrm{O}) \mathrm{CHCl}$. The fit is calculated from the $P\left(E_{\mathrm{T}}\right)$ distribution shown in Figure 11, which was derived from fitting the time-of-flight of the $\mathrm{CH}_{3}$ coproduct of this reaction assuming only the highest internal energy ground state $\mathrm{CH}_{3} \mathrm{C}(\mathrm{O}) \mathrm{CHCl}$ radicals dissociate to these products (see text). (b) The same data are shown, but the signal with arrival times earlier than $100 \mu \mathrm{s}$ is fit as a secondary dissociation following a primary $\mathrm{HCl}$ elmination channel, corresponding to the $P\left(E_{\mathrm{T}}\right)$ in Figure 13. (c) The same data are shown, but the signal with arrival times earlier than $100 \mu \mathrm{s}$ is now fit by assuming that acetyl product from a potential primary $\mathrm{C}-\mathrm{C}$ fission channel contributes to the spectrum, according to the $P\left(E_{\mathrm{T}}\right)$ in Figure 15 . 


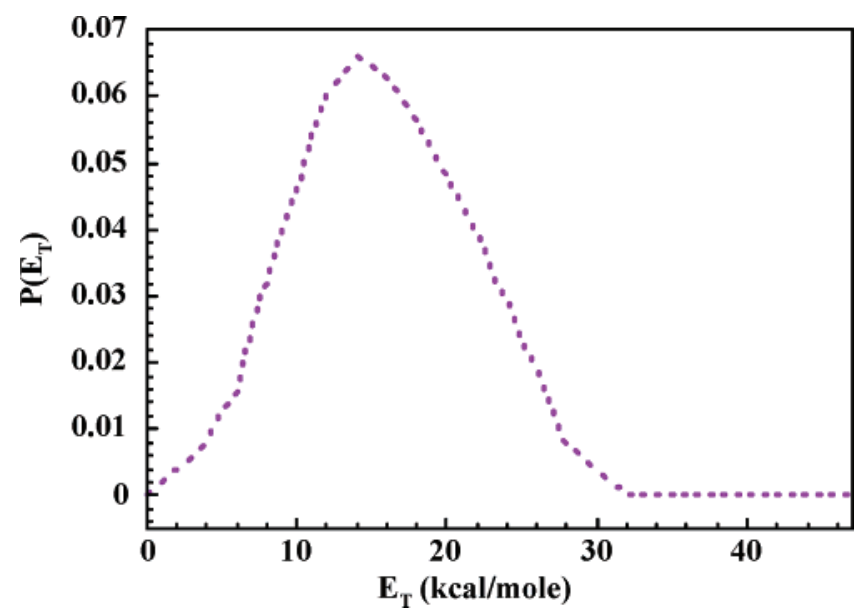

Figure 13. The $P\left(E_{\mathrm{T}}\right)$ describing cleavage of a cyclic intermediate of $\mathrm{CH}_{2}(\mathrm{O}) \mathrm{CCHCl}$, which isomerizes to $\mathrm{CH}(\mathrm{O}) \mathrm{CCH}_{2} \mathrm{Cl}$ and dissociates to give $\mathrm{HCCO}+\mathrm{CH}_{2} \mathrm{Cl}$, is given in the dotted line. This distribution was derived through fitting the $m / e=41$ data shown in Figure 12 and is also used to fit the $m / e=28$ data shown in Figure $6 \mathrm{a}, \mathrm{c}$ and the $m / e$ $=14$ data shown in Figure 14 .

fast to correspond to the unimolecular dissociation products of any of the vibrationally excited photofragments formed from primary $\mathrm{HCl}$ elimination or $\mathrm{C}-\mathrm{Cl}$ fission unless a two-photon absorption is involved. In Figure 12b, we attempt to fit this signal by assuming it arises from the cleavage of a cyclical intermediate form of the $\mathrm{CH}_{2} \mathrm{COCHCl}$ radical product of $\mathrm{HCl}$ elimination, assuming that a three-membered ring forms among the three carbons and allows a 1,2 hydride shift to give $\mathrm{CHCOCH}_{2} \mathrm{Cl}$. Secondary dissociation of this molecule to give the ketenyl radical ( $\mathrm{HCCO}$ ) and $\mathrm{CH}_{2} \mathrm{Cl}$ is described by the $P\left(E_{\mathrm{T}}\right)$ shown in Figure 13. The $P\left(E_{\mathrm{T}}\right)$ for this secondary dissociation process extends from $0-32 \mathrm{kcal} / \mathrm{mol}$, peaking at $14 \mathrm{kcal} / \mathrm{mol}$. A portion of this signal shows up at $m / e=28\left(\mathrm{CO}^{+}\right)$, as shown in Figure $6 \mathrm{a}$ and c. This signal shows up more strongly at the higher photoionization energy, $16 \mathrm{eV}$, than at the lower photoionization energy, $12.5 \mathrm{eV}$, which is consistent with the signal arising from dissociative photoionization that forms $\mathrm{CO}^{+}$ from a larger fragment, as we postulate. Further support for this channel comes from the fact that the small amount of $m / e$ $=14$ data collected can be fit as the dissociative ionization of the $\mathrm{CH}_{2} \mathrm{Cl}$ cofragment to the ketenyl radical, as shown in Figure 14.

An alternate explanation for the fast signal at $m / e=41$ is a primary dissociation channel involving cleavage of the $\mathrm{C}-\mathrm{C}$ bond in $\mathrm{CH}_{3} \mathrm{C}(\mathrm{O}) \mathrm{CHCl}_{2}$ to give an acetyl radical, $\mathrm{CH}_{3} \mathrm{CO}$, and $\mathrm{CHCl}_{2}$ (Figure $12 \mathrm{c}$ ). The $P\left(E_{\mathrm{T}}\right)$ required to fit this signal assuming it arises from such a primary $\mathrm{C}-\mathrm{C}$ fission channel is broad and extends from 5 to $38 \mathrm{kcal} / \mathrm{mol}$, peaking at $15 \mathrm{kcal} /$ mol (Figure 15). The $m / e=28$ spectrum in Figure $6 \mathrm{~b}$ also shows signal that can be fit assuming it arises from dissociative ionization of the acetyl radical from this primary $\mathrm{C}-\mathrm{C}$ bond fission channel. This process underfits the fast side of the $m / e$ $=28$ data; however, we cannot completely rule out two-photon processes showing up in these spectra. Unpublished work in our lab finds that $157 \mathrm{~nm}$ photoionzation of $\mathrm{CH}_{3} \mathrm{CO}$ photofragments from acetyl chloride photodissociation evidence exclusively signal at $m / e=43\left(\mathrm{CH}_{3} \mathrm{CO}^{+}\right)$, not $m / e=41$. For this reason, we are hesitant to assign the $m / e=41$ signal to a daughter fragment of $\mathrm{CH}_{3} \mathrm{CO}^{+}$. However, the $m / e=41$ data in Figure 12 were taken at a substantially higher photoionzation energy $(11.3 \mathrm{eV})$. Thus, it is possible that at this higher photoionzation energy, $\mathrm{H}_{2}$ elimination from the molecular ion leads to substantial signal at $\mathrm{HCCO}^{+}$and a corresponding

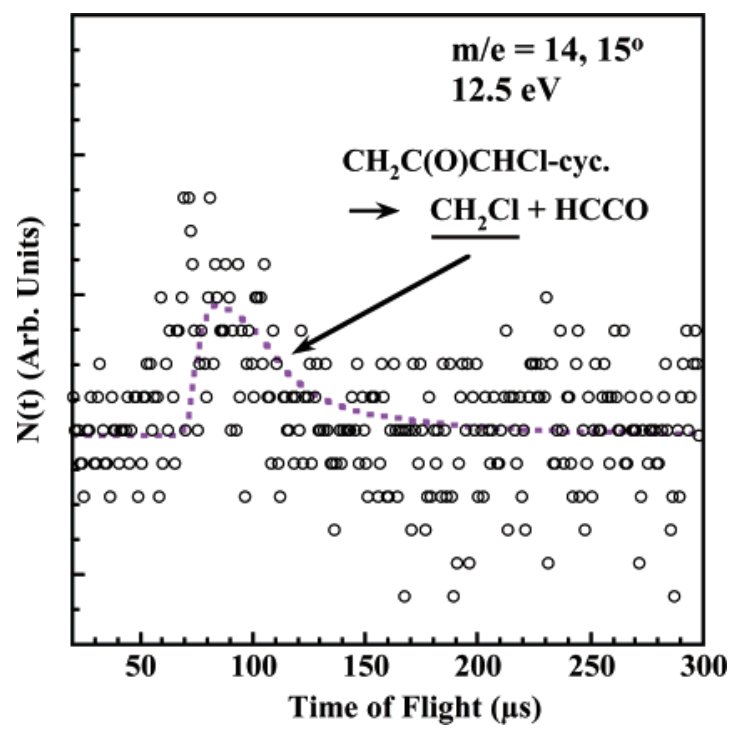

Figure 14. TOF spectra at $m / e=14\left(\mathrm{CH}_{2}^{+}\right)$. Signal was taken at a $15^{\circ}$ source angle, $12.5 \mathrm{eV}$ photoionization energy, and $3 \mathrm{~mJ}$ (external, lower power) at the ALS. The higher ALS resolution range was used (see the Experimental Section). We obtained the forward convolution fit to these data, shown in the thin dashed line, from the $P\left(E_{\mathrm{T}^{-}}\right)$shown in Figure 13. Open circles show experimental data.

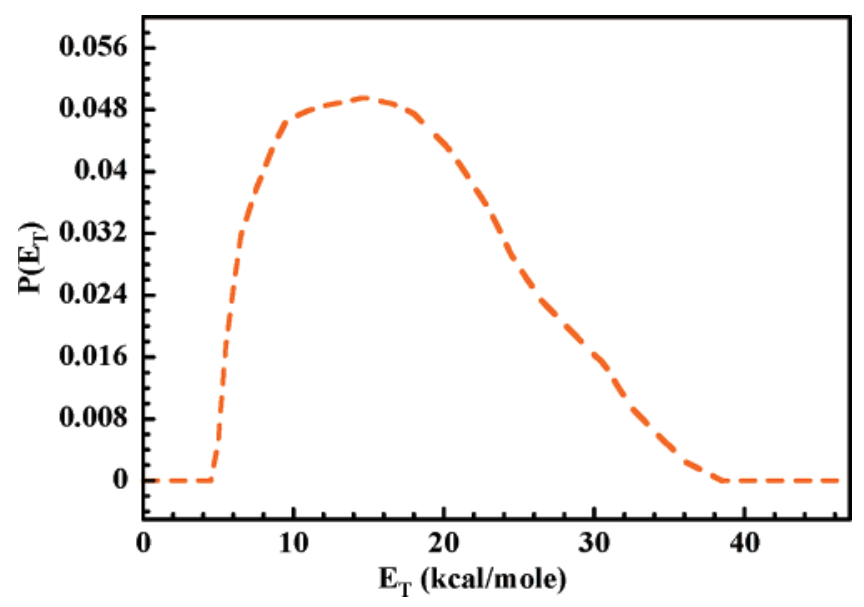

Figure 15. The $P\left(E_{\mathrm{T}}\right)$ describing cleavage of the $\mathrm{CH}_{3}(\mathrm{O}) \mathrm{C}-\mathrm{CHCl}_{2}$ bond to form $\mathrm{CH}_{3} \mathrm{C}(\mathrm{O})+\mathrm{CHCl}_{2}$ is given in the thin, dashed line. This distribution was derived through fitting the $m / e=41$ data shown in Figure $12 \mathrm{c}$ and is also used to fit the $m / e=28$ data shown in Figure $6 b$.

depletion of signal at $m / e=43$. Such a dissociative ionization process is not unprecedented; indeed, $\mathrm{CH}_{3} \mathrm{O}$ radicals do not give significant signal at parent ion or parent ion -1 , but rather give strong signal at $m / e=29$ due to a predissociation of the ion to $\mathrm{CHO}^{+}+\mathrm{H}_{2} \cdot{ }^{30}$ The confirmation of this assignment awaits a better understanding of the photoionization of the acetyl radical. There has been some prior work involving photoionization of the acetyl radical, but a recent study by Leach et al. has called this prior work into question. ${ }^{31}$

In this study, we were particularly interested in examining the possibility that an elimination channel giving $\mathrm{Cl}_{2}+\mathrm{CH}_{3}$ $\mathrm{COCH}$ might yield a carbene reaction intermediate, $\mathrm{CH}_{3} \mathrm{COCH}$, of the $\mathrm{O}+$ propyne reaction. Data were taken using the pulsed molecular beam nozzle at Chicago and keeping the laser power at $3 \mathrm{~mJ}$, or about $10 \%$ of the saturation level. After 3.25 million laser shots, there was no discernible signal at $m / e=70$. Signal observed at $m / e=70$ following photolysis at higher laser powers at Chicago was clearly assigned to multiphoton effects on the basis of an energetic analysis. There was also no obvious peak 


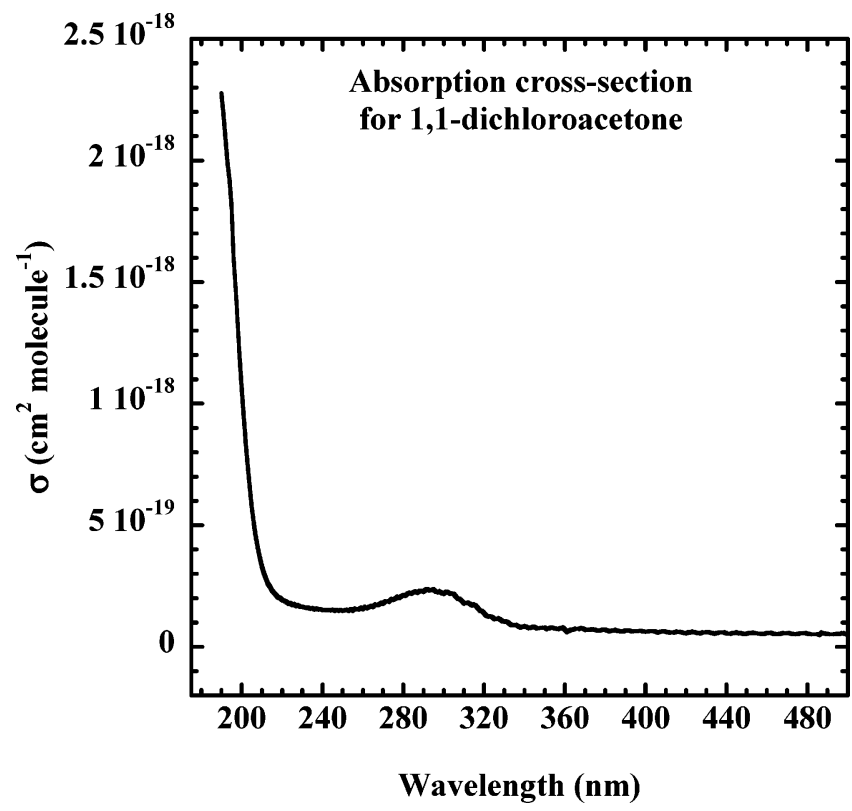

Figure 16. UV-vis absorption spectrum of 1,1-dichloroacetone vapor, recorded at $298{ }^{\circ} \mathrm{C}$ from 190 to $500 \mathrm{~nm}$.

at $m / e=70$ after 150000 laser shots at $11.8 \mathrm{eV}$ and 134000 laser shots at $12.8 \mathrm{eV}$ at the ALS. We conclude that if a $\mathrm{Cl}_{2}$ elimination channel exists, it is too minor to detect using our experimental apparatus.

In order to quantify how close to saturation we are at any given laser power, it is necessary to know the $193 \mathrm{~nm}$ absorption cross section for 1,1-dichloroacetone. Because we could not find this value in the literature, we measured the UV-vis absorption curve as described in the Experimental Section. The absorption spectrum in Figure 16 exhibits at least two peaks in the ultraviolet region: one major peak that extends below the cutoff of our measurements at $190 \mathrm{~nm}$ and a smaller peak centered at $\sim 292 \mathrm{~nm}$. We calculate the absorption cross section to be $\sigma_{193} \mathrm{~nm}$ $=2 \times 10^{-18} \mathrm{~cm}^{2}$ molecule ${ }^{-1}$. Our spectrum is in qualitative agreement with the three previous studies that have examined the ultraviolet absorption of 1,1-dichloroacetone. Mountcastle et al. found an ultraviolet absorption peak to be centered at 295 $\mathrm{nm}$, close to the $292 \mathrm{~nm}$ peak we measured. ${ }^{21}$ Smith et al. observed two peaks in the spectrum: one that was still increasing at their cutoff wavelength of $\sim 210 \mathrm{~nm}$ and another that was located in the region around $290 \mathrm{~nm}$ (no exact wavelength values were given). ${ }^{19}$ Carr et al. also have a peak in the $295 \mathrm{~nm}$ region (exact values not given); their spectrum does not extend far enough to detect the other, lower wavelength, absorption.

Information on the internal energy of the photofragments following photodissociation is obtained through conservation of energy.

$$
E_{\text {parent }}+E_{\mathrm{h} v}=D_{0}+E_{\text {int }}+E_{\mathrm{T}}
$$

We assume that rotations are effectively cooled in the molecular beam and $E_{\text {parent }}$ can be approximated by the vibrational energy at the nozzle temperature. This was calculated to range from 3 to $6 \mathrm{kcal} / \mathrm{mol}$ for the range of nozzle temperatures used in this study. $E_{\mathrm{h} v}$ is the energy of the $193.3 \mathrm{~nm}$ excitation photon (147.8 $\mathrm{kcal} / \mathrm{mol}$ with an air-to-vacuum correction). For secondary dissociation, eq 4 applies with $E_{\text {parent }}$ replaced by the available internal energy of the primary fragment and $E_{\mathrm{h} v}=0$. We were unable to find bond dissociation energies, $D_{0}$, for 1,1-dichloroacetone in previous studies, so we calculated them through heats of formation at $0 \mathrm{~K}$ using Gaussian 03 at the G3//B3LYP
TABLE 1: Dissociation Energies Calculated at the G3B3 Level for Several Possible Dissociation Channels of 1,1-Dichloroacetone ${ }^{a}$

\begin{tabular}{lcc}
\hline \multicolumn{1}{c}{ reaction channel } & $\begin{array}{c}D_{0} \\
(\mathrm{kcal} / \mathrm{mol})\end{array}$ & $\begin{array}{c}E_{\text {avl }} \\
(\mathrm{kcal} / \mathrm{mole}) \\
65{ }^{\circ} \mathrm{C}\end{array}$ \\
\hline $\mathrm{CH}_{3} \mathrm{C}(\mathrm{O}) \mathrm{CHCl}_{2} \rightarrow \mathrm{CH}_{3} \mathrm{C}(\mathrm{O}) \mathrm{CHCl}+\mathrm{Cl}$ & 67.2 & 84.0 \\
$\mathrm{CH}_{3} \mathrm{C}(\mathrm{O}) \mathrm{CHCl} \rightarrow \mathrm{CH}_{3}+\mathrm{C}(\mathrm{O}) \mathrm{CHCl} \mathrm{(2^{ \circ } )}$ & 42.7 & 41.3 \\
$\mathrm{CH}_{3} \mathrm{C}(\mathrm{O}) \mathrm{CHCl} \mathrm{CH}_{2} \rightarrow \mathrm{CH}_{2} \mathrm{C}(\mathrm{O}) \mathrm{CHCl}+\mathrm{HCl}$ & 62.8 & 88.4 \\
$\mathrm{CH}_{3} \mathrm{C}(\mathrm{O}) \mathrm{CHCl}_{2} \rightarrow \mathrm{CH}_{3} \mathrm{C}(\mathrm{O}) \mathrm{CCl}(\mathrm{s})+\mathrm{HCl}$ & 68.5 & 82.7 \\
$\mathrm{CH}_{3} \mathrm{C}(\mathrm{O}) \mathrm{CHCl}_{2} \rightarrow \mathrm{CH}_{3} \mathrm{C}(\mathrm{O}) \mathrm{CCl}(\mathrm{t})+\mathrm{HCl}$ & 70.4 & 80.8 \\
$\mathrm{CH}_{2} \mathrm{C}(\mathrm{O}) \mathrm{CHCl} \rightarrow \mathrm{HCCO}^{\circ} \mathrm{CH}_{2} \mathrm{Cl}\left(2^{\circ}\right)$ & 38.7 & 49.7 \\
$\mathrm{CH}_{3} \mathrm{C}(\mathrm{O}) \mathrm{CHCl}_{2} \rightarrow \mathrm{CH}_{3} \mathrm{CO}+\mathrm{CHCl}_{2}$ & 75.3 & 76.0 \\
$\mathrm{CH}_{3} \mathrm{C}(\mathrm{O}) \mathrm{CHCl}_{2} \rightarrow \mathrm{CH}_{3}+\mathrm{C}(\mathrm{O}) \mathrm{CHCl}$ & 84.8 & 66.4 \\
$\mathrm{CH}_{3} \mathrm{C}(\mathrm{O}) \mathrm{CHCl}_{2} \rightarrow \mathrm{CH}_{3} \mathrm{C}(\mathrm{O}) \mathrm{CH}(\mathrm{s})+\mathrm{Cl}_{2}$ & 105.7 & 45.5 \\
$\mathrm{CH}_{3} \mathrm{C}(\mathrm{O}) \mathrm{CHCl}_{2} \rightarrow \mathrm{CH}_{3} \mathrm{C}(\mathrm{O}) \mathrm{CH}(\mathrm{t})+\mathrm{Cl}_{2}$ & 105.9 & 45.3
\end{tabular}

${ }^{a} E_{\mathrm{avl}}=E_{\mathrm{int}}+E_{\mathrm{T}}$. For secondary processes, $E_{\mathrm{avl}}$ for the final products is given for the energy corresponding to the available energy in the nascent radical and does not subtract out the experimentally measured translational energy imparted to the radicals during the primary dissociation. When reaction channels involve secondary dissociation, this is indicated after the reaction. See text for more information about the calculations.

TABLE 2: Internal Energy Range Calculated for the Observed Dissociation Channels ${ }^{a}$

\begin{tabular}{lrc}
\hline \multicolumn{1}{c}{ reaction channel } & \multicolumn{1}{c}{$\begin{array}{c}E_{\mathrm{T}} \\
(\mathrm{kcal} / \mathrm{mol})\end{array}$} & $\begin{array}{c}E_{\text {int }} \\
(\mathrm{kcal} / \mathrm{mole}) \\
\text { at } 655^{\circ} \mathrm{C}\end{array}$ \\
\hline $\mathrm{I} . \mathrm{CH}_{3} \mathrm{C}(\mathrm{O}) \mathrm{CHCl}_{2} \rightarrow \mathrm{CH}_{3} \mathrm{C}(\mathrm{O}) \mathrm{CHCl}+\mathrm{Cl}$ & $0-30$ & $54-84$ \\
$\mathrm{II}_{\mathrm{CH}} \mathrm{C}(\mathrm{O}) \mathrm{CHCl}_{2} \rightarrow \mathrm{CH}_{3} \mathrm{C}(\mathrm{O}) \mathrm{CHCl}+\mathrm{Cl}$ & $13-45$ & $39-71$ \\
$\mathrm{CH}_{3} \mathrm{C}(\mathrm{O}) \mathrm{CHCl} \rightarrow \mathrm{CH}_{3}+\mathrm{C}(\mathrm{O}) \mathrm{CHCl}\left(2^{\circ}\right)$ & $3-14$ & $27-38$ \\
$\mathrm{I}_{\mathrm{CH}} \mathrm{C}(\mathrm{O}) \mathrm{CHCl} \mathrm{CH}_{2} \rightarrow \mathrm{CH}_{2} \mathrm{C}(\mathrm{O}) \mathrm{CHCl}+\mathrm{HCl}^{b}$ & $0-11$ & $77-88$ \\
$\mathrm{II}_{\mathrm{CH}} \mathrm{CH}_{3} \mathrm{C}(\mathrm{O}) \mathrm{CHCl}_{2} \rightarrow \mathrm{CH}_{2} \mathrm{C}(\mathrm{O}) \mathrm{CHCl}+\mathrm{HCl}^{b}$ & $9-36$ & $52-79$ \\
$\mathrm{CH}_{2} \mathrm{C}(\mathrm{O}) \mathrm{CHCl} \rightarrow \mathrm{HCCO}^{-} \mathrm{CH}_{2} \mathrm{Cl}\left(2^{\circ}\right)$ & $0-32$ & $18-50$ \\
$\mathrm{CH}_{3} \mathrm{C}(\mathrm{O}) \mathrm{CHCl}_{2} \rightarrow \mathrm{CH}_{3} \mathrm{CO}+\mathrm{CHCl}_{2}$ & $5-38$ & $38-71$
\end{tabular}

${ }^{a}$ Components of bimodel distributions are designated as I (low recoil kinetic energy portion) and II (high recoil kinetic energy portion). When reaction channels involve secondary dissociation, this is indicated after the reaction. ${ }^{b}$ We have not definitively assigned which $\mathrm{HCl}$ elimination process precedes these channels; the lowest energy primary process is used for calculations of $E_{\text {int }}$.

level of theory (Table 1). The average absolute deviation of G3//B3LYP calculated heats of formation against the G2/97 test set (148 enthalpy values) is $0.93 \mathrm{kcal} / \mathrm{mol},{ }^{23}$ but the system presented here is larger than most molecules in the test set. Several recent projects in our group have used G3//B3LYP to examine a variety of compounds that differ from the test set in being larger or radicals. These calculations are often linked with experimental measurements that, for neutrals and simple radicals, generally agree to within our machine resolution of $\sim 2 \mathrm{kcal} / \mathrm{mol}$. For example, measurements of the barrier to $\mathrm{C}-\mathrm{C}$ and $\mathrm{C}-\mathrm{H}$ bond fission for three $\mathrm{C}_{4} \mathrm{H}_{7}$ unsaturated hydrocarbons agreed to within $2 \mathrm{kcal} / \mathrm{mol}$ in recent work. ${ }^{32-34}$ With our measurements of $E_{\mathrm{T}}$ and the calculated values of $D_{0}$, we use eq 4 to determine the range of $E_{\text {int }}$, corresponding to the dissociation channels observed. These values are given in Table 2 .

\section{Discussion}

The $\mathrm{C}-\mathrm{Cl}$ fission primary reaction channel resulted in photofragments with two distinct energy distributions. The lower kinetic energy channel likely corresponds to $\mathrm{Cl}$ plus an electronically excited radical, in analogy with several recent studies of the photodissociation of chlorinated species at 193 $\mathrm{nm}$ (see, for example, refs 35,36 ). Both $\mathrm{C}-\mathrm{Cl}$ bond fission channels result in photofragments with high internal energies; the two pathways form fragments with $39-71$ and $54-84 \mathrm{kcal} /$ 
mol of internal energy, respectively. The velocity map ion imaging data clearly show that $\mathrm{Cl}$ is formed in both the ground, $\mathrm{Cl}\left({ }^{2} \mathrm{P}_{3 / 2}\right)$, and spin-orbit excited state, $\mathrm{Cl}\left({ }^{2} \mathrm{P}_{1 / 2}\right)$, which are separated by $2.5 \mathrm{kcal} / \mathrm{mol}$. The low kinetic energy release $\mathrm{C}-\mathrm{Cl}$ bond fission channel produces primarily $\mathrm{Cl}$ atoms in the ground spin-orbit state, whereas the high kinetic energy release $\mathrm{C}-\mathrm{Cl}$ bond fission channel produces a mixture of ground and excited spin-orbit state $\mathrm{Cl}$ atoms. The two distributions evidence similar angular distributions with respect to the electric vector of the dissociating laser light.

The data also suggest that the $\mathrm{HCl}$ elimination reaction channel leads to photoproducts with two separate energy distributions. The $\mathrm{HCl}$ elimination channel produces fragments with substantial internal energies of 52-79 and 77-88 kcal/ mol, respectively. The next highest electronic state of hydrogen chloride lies $125 \mathrm{kcal} / \mathrm{mol}$ above the ground state, which is energetically inaccessible in this experiment. We were unable to find literature information about the energetics of the possible cofragments, $\mathrm{CH}_{2} \mathrm{C}(\mathrm{O}) \mathrm{CHCl}$ or $\mathrm{CH}_{3} \mathrm{C}(\mathrm{O}) \mathrm{CCl}$, but an excited electronic state may be formed in one of the two $\mathrm{HCl}$ elimination channels observed. It is also possible that the two distributions correspond to different types of $\mathrm{HCl}$ elimination: three-center vs five-center.

Photofragment translational spectroscopy with electron impact ionization showed the branching between $\mathrm{C}-\mathrm{Cl}$ fission reaction and $\mathrm{HCl}$ elimination to be roughly $9: 1$ at a nozzle temperature of $200^{\circ}$. Energetically, these two processes are similar, requiring a minimum of 67.2 and $68.5 \mathrm{kcal} / \mathrm{mol}$, respectively. Our work here does not explore whether this branching ratio is different for the two conformers of 1,1-dichloroacetone, as is the case for chloroacetone and bromoacetone excited at $308 \mathrm{~nm}^{1,3}$ In both of these molecules, the reaction pathways access regions of phase space near a conical intersection. The dissociation dynamics are strongly affected by nonadiabatic recrossing of reaction barriers in the vicinity of the conical intersection. This effect is conformation-dependent, leading to a temperature dependence to branching. In light of these studies, care should be taken in extrapolating the branching ratio presented here to other conditions.

Previous studies in our laboratory have examined the photodissociation dynamics of the halogenated acetones chloroacetone $^{1,2}$ and bromoacetone ${ }^{3}$ at a lower excitation energy of $308 \mathrm{~nm}$. Following excitation at this wavelength, chloroacetone $\left(\mathrm{CH}_{3} \mathrm{C}(\mathrm{O}) \mathrm{CH}_{2} \mathrm{Cl}\right)$ undergoes two bond fission channels that have a 4.63:1 branching ratio at $180{ }^{\circ} \mathrm{C}, \mathrm{C}-\mathrm{Cl}$ bond fission and cleavage of the $\mathrm{C}-\mathrm{C}$ bond to give $\mathrm{CH}_{3} \mathrm{CO}+\mathrm{CH}_{2} \mathrm{Cl}$. Although the absolute branching was not measured for bromoacetone, photolysis at $308 \mathrm{~nm}$ resulted in the two analogous channels, $\mathrm{C}-\mathrm{Br}$ bond fission and cleavage of the $\mathrm{C}-\mathrm{C}$ bond to give $\mathrm{CH}_{3} \mathrm{CO}+\mathrm{CH}_{2} \mathrm{Br}$. Hydrogen halide formation was not significant in either case. The presence of an $\mathrm{HCl}$ elimination channel following $193 \mathrm{~nm}$ photolysis of 1,1-chloroacetone may be due to differences between the mono- and dihalogenated species, but it is more likely to be caused by the dynamics in the higher energy absorption band accessed in this experiment. Future experiments photolyzing the monohalogenated species at higher energies might reveal hydrogen halide elimination channels. Such information would potentially be useful for atmospheric modeling.

One of two tentative assignments of the signal at $m / e=41$ and $m / e=28$ is to a $\mathrm{C}-\mathrm{C}$ bond fission channel leading to the acetyl radical and a halogenated cofragment, analogous to those observed in the monohalogenated acetones. As discussed in the Results Section, further support for this assignment awaits a better understanding of the dissociative ionization of the acetyl radical. Because acetyl radicals can easily dissociate into $\mathrm{CH}_{3}$ $+\mathrm{CO}$ (the barrier is only $\sim 15 \mathrm{kcal} / \mathrm{mol}$ ), most of the fragments resulting from the postulated $\mathrm{C}-\mathrm{C}$ fission channel are expected to have enough internal energy to undergo secondary dissociation if formed in the ground state of the acetyl radical, as we estimate in internal energy range of the secondary products $\mathrm{CH}_{3} \mathrm{CO}+\mathrm{CHCl}_{2}$ to be $38-71 \mathrm{kcal} / \mathrm{mol}$. This process was tried and rejected, however, as an explanation for the data appearing at $m / e=15$. The first excited state $\mathrm{A}^{2} \mathrm{~A}^{\prime \prime}\left(1^{2} \mathrm{~A}^{\prime \prime}\right)$ may also be energetically accessible, because the vertical excitation energy from to this state from the ground state was calculated to be $60.0 \mathrm{kcal} / \mathrm{mol}$ via MR(SD)CI calculations.

The peaks in the absorption spectrum for 1,1-dichloroacetone have not been assigned to specific electronic states. We are unaware of any computational work that attempts to characterize the excited electronic states of 1,1-dichloroacetone. In analogy with acetone however, we expect that the peak near $190 \mathrm{~nm}$ corresponds to a $\pi \pi^{*}$ absorption.

Our G3//B3LYP calculations of bond dissociation energies appear reasonable when compared to energetics of similar systems. Because the primary photofragments were formed with substantial amounts of internal energy in all cases, however, the energy distributions derived from our experimental measurements cannot be used to evaluate the calculated dissociation energies.

Although we initially hoped to use 1,1-dichloroacetone as a photolytic precursor to the $\mathrm{CH}_{3} \mathrm{COCH}$ radical via $\mathrm{Cl}_{2}$ elimination, we were unable to observe $\mathrm{Cl}_{2}$ elimination as a result of single photon excitation. Our observation of a substantial amount of $\mathrm{HCl}$ elimination, however, points to an alternate precursor to the desired carbene. If the monohalogenated chloroacetone molecule also exhibits $\mathrm{HCl}$ elimination following $193 \mathrm{~nm}$ photolysis, this would provide an alternate $\mathrm{CH}_{3} \mathrm{COCH}$ radical precursor.

Acknowledgment. The National Science Foundation supported this work under grant CHE-0403471 (L.J.B.). The Advanced Light Source is supported by the Director, Office of Science, Office of Basic Energy Sciences, Materials Sciences Division, of the U.S. Department of Energy under Contract No. DE-AC03-76SF00098 at Lawrence Berkeley National Laboratory. The Chemical Dynamics Beamline is supported by the Director, Office of Science, Office of Basic Energy Sciences, Chemical Sciences Division of the U.S. Department of Energy under the same contract. The authors thank J. Shu for assistance at the Advanced Light Source and B. Falli for performing initial calculations on 1,1-dichloroacetone. We appreciate tutoring in Fieller's method from P. McCullagh, M. Wang, and M. Stein. L.R.M. acknowledges a GAANN fellowship for salary support during a portion of this work, M.J.B. acknowledges support from a Jean Dreyfus Boissevain Undergraduate Scholarship for Excellence in Chemistry, and M.J.K. acknowledges an ARCS scholarship.

\section{References and Notes}

(1) Waschewsky, G. C. G.; Kash, P. W.; Myers, T. L.; Kitchen, D. C.; Butler, L. J. J. Chem. Soc. Faraday Trans. 1994, 90, 1581.

(2) Kitchen, D. C.; Myers, T. L.; Butler, L. J. J. Phys. Chem. 1996, 100,5200 .

(3) Kash, P. W.; Waschewsky, G. C. G.; Morss, R. E.; Butler, L. J.; Francl, M. M. J. Chem. Phys. 1994, 100, 3463.

(4) Burkholder, J. B.; Gilles, M. K.; Gierczak, T.; Ravishankara, A. R. Geophys. Res. Lett. 2002, 29, 1822.

(5) Williams, J. A.; Cooper, W. J.; Mezyk, S. P.; Bartels, D. M. Rad. Phys. Chem. 2002, 65, 327. 
(6) Chiba, T. Bull. Chem. Soc. Jpn. 1954, 28, 19.

(7) Bostrøm, G. O.; Bakken, P.; Stølevik, R. J. Mol. Struct. 1987, 158, 23.

(8) Durig, J. R.; Hardin, J. A.; Tolley, C. L. J. Mol. Struct. 1990, 1990, 323

(9) Hagen, K.; Shen, Q.; Carter, R.; Marion, M. J. Phys. Chem. A 2002, $106,4263$.

(10) Guthrie, J. P. J. Am. Chem. Soc. 2000, 122, 5529

(11) Notario, A.; Mellouki, A.; Le, Bras, G. Int. J. Chem. Kinet. 1999 32,62

(12) Xing, G.; Huang, X.; Wang, X.; Bersohn, R. J. Chem. Phys. 1996, $105,488$.

(13) Schmoltner, A. M.; Chu, P. M.; Lee, Y. T. J. Chem. Phys. 1989 91,5365 .

(14) Harding, L. B.; Wagner, A. F. J. Phys. Chem. 1986, 90, 2974.

(15) Yarkony, D. R. J. Phys. Chem. A 1998, 102, 5305.

(16) Heimann, P. A.; Koike, M.; Hsu, C. W.; Blank, D.; Yang, X. M.; Suits, A. G.; Lee, Y. T.; Evans, M.; Ng, C. Y.; Flaim, C.; Padmore, H. A Rev. Sci. Instrum. 1997, 68, 1945.

(17) Peterka, D.; Ahmed, M. Personal communication, 2002.

(18) Lau, K.-C.; Liu, Y.; Butler, L. J. J. Chem. Phys. 2005, 123, 054322

(19) Smith, E. D.; Thornsberry, W. L. J. Chem. Eng. Data 1970, 15 296.

(20) Carr, S.; Shallcross, D. E.; Canosa-Mas, C. E.; Wenger, J. C.; Sidebottom, H. W.; Treacy, J. J.; Wayne, R. P. Phys. Chem. Chem. Phys. 2003, 5,3874 .

(21) Mountcastle, W. R. J.; Smith, D. F.; Grove, E. L. J. Chem. Phys. 1956, 25, 1342

(22) Frisch, M. J.; Trucks, G. W.; Schlegel, H. B.; Scuseria, G. E.; Robb, M. A.; Cheeseman, J. R.; Montgomery, J. J. A.; Vreven, T.; Kudin, K. N.; Burant, J. C.; Milliam, J. M.; Iyengar, S. S.; Tomasi, J.; Barone, V.; Mennucci, B.; Cossi, M.; Scalmani, G.; Rega, N.; Petersson, G. A.; Nakatsuji, H.; Hada, M.; Ehara, M.; Toyota, K.; Fukuda, R.; Hasegawa, J.; Ishida, M.; Nakajima, T.; Honda, Y.; Kitao, O.; Nakai, H.; Klene, M.; Li, X.; Knox, J. E.; Hratchian, H. P.; Cross, J. B.; Bakken, V.; Adamo, C.
Jaramillo, J.; Gomperts, R.; Stratmann, R. E.; Yazyev, O.; Austin, A. J.; Cammi, R.; Pomelli, C.; Ochterski, J. W.; Ayala, P. Y.; Morokuma, K.; Voth, G. A.; Salvador, P.; Dannenberg, J. J.; Zakrzewski, V. G.; Dapprich, S.; Daniels, A. D.; Strain, M. C.; Farkas, O.; Malick, D. K.; Rabuck, A. D.; Raghavachari, K.; Foresman, J. B.; Ortiz, J. V.; Cui, Q.; Baboul, A. G.; Clifford, S.; Cioslowski, J.; Stefanov, B. B.; Liu, G.; Liashenko, A.; Piskorz, P.; Komaromi, I.; Martin, R. L.; Fox, D. J.; Keith, T.; Al-Laham, M. A.; Peng, C. Y.; Nanayakkara, A.; Challacombe, M.; Gill, P. M. W.; Johnson, B.; Chen, W.; Wong, M. W.; Gonzalez, C.; Pople, J. A. Gaussian 03, Revision C.02; Gaussian, Inc.: Wallingford, CT, 2004.

(23) Baboul, A. G.; Curtiss, L. A.; Redfern, P. C.; Raghavachari, K. J. Chem. Phys. 1999, 110, 7650.

(24) Harper, S.; Calandra, P.; Price, S. D. Phys. Chem. Chem. Phys. 2001, 3, 741.

(25) McCunn, L. R.; Bennett, D. I. G.; Butler, L. J.; Fan, H.; Aguirre, F.; Pratt, S. T. J. Phys. Chem. A 2006, 110, 843.

(26) Liyanage, R.; Yang, Y. A.; Hashimoto, S.; Gordon, R. J.; Field, R. W. J. Chem. Phys. 1995, 103, 6811.

(27) Zare, R. N. Mol. Photochem. 1972, 4, 1.

(28) Fieller, E. C. J. R. Stat. Soc., Ser. B 1954, 16, 175.

(29) Center, R. E.; Mandl, A. J. Chem. Phys. 1972, 57, 4104.

(30) Harvey, J. N.; Aschi, M. Phys. Chem. Chem. Phys. 1999, 1, 5555

(31) Leach, S.; Schwell, M.; Jochims, H.-W.; Baumgärtel, H. Chem. Phys. 2006, 321, 171.

(32) Miller, J. L.; McCunn, L. R.; Krisch, M. J.; Butler, L. J.; Shu, J. J. Chem. Phys. 2004, 121, 1830.

(33) Miller, J. L.; Krisch, M. J.; Butler, L. J.; Shu, J. J. Phys. Chem. A 2005, 109, 4038 .

(34) McCunn, L. R.; Krisch, M. J.; Liu, Y.; Butler, L. J.; Shu, J. J. Phys. Chem. A 2005, 109, 6430.

(35) McCunn, L. R.; Lau, K.-C.; Krisch, M. J.; Butler, L. J.; Tsung, J.-W.; Lin, J. J. J. Phys. Chem. A 2006, 110, 1625.

(36) Bell, M. J.; Lau, K.-C.; Krisch, M. J.; Bennett, D. I. G.; Butler, L. J.; Weinhold, F. J. Phys. Chem. A 2007, 111, 1762. 